\title{
STAT1-deficient mice spontaneously develop estrogen receptor $\alpha$-positive luminal mammary carcinomas
}

Szeman Ruby Chan ${ }^{1}$, William Vermi ${ }^{2}$, Jingqin Luo ${ }^{3}$, Laura Lucini ${ }^{2}$, Charles Rickert ${ }^{1}$, Amy M Fowler ${ }^{4}$, Silvia Lonardi ${ }^{2}$, Cora Arthur ${ }^{1}$, Larry JT Young ${ }^{5}$, David E Levy ${ }^{6}$, Michael J Welch ${ }^{4}$, Robert D Cardiff ${ }^{5}$ and Robert D Schreiber ${ }^{*}$

\begin{abstract}
Introduction: Although breast cancers expressing estrogen receptor- $\alpha$ (ER $\alpha)$ and progesterone receptors (PR) are the most common form of mammary malignancy in humans, it has been difficult to develop a suitable mouse model showing similar steroid hormone responsiveness. STAT transcription factors play critical roles in mammary gland tumorigenesis, but the precise role of STAT1 remains unclear. Herein, we show that a subset of human breast cancers display reduced STAT1 expression and that mice lacking STAT1 surprisingly develop ER $\alpha+$ /PR+ mammary tumors.
\end{abstract}

Methods: We used a combination of approaches, including histological examination, gene targeted mice, gene expression analysis, tumor transplantaion, and immunophenotyping, to pursue this study.

Results: Forty-five percent (37/83) of human ER $\alpha+$ and 22\% (17/78) of ER $\alpha$ - breast cancers display undetectable or low levels of STAT1 expression in neoplastic cells. In contrast, STAT1 expression is elevated in epithelial cells of normal breast tissues adjacent to the malignant lesions, suggesting that STAT1 is selectively downregulated in the tumor cells during tumor progression. Interestingly, the expression levels of STAT1 in the tumorinfiltrating stromal cells remain elevated, indicating that single-cell resolution analysis of STAT1 level in primary breast cancer biopsies is necessary for accurate assessment. Female mice lacking functional STAT1 spontaneously develop mammary adenocarcinomas that comprise $>90 \% \mathrm{ER} \alpha+/ \mathrm{PR}+$ tumor cells, and depend on estrogen for tumor engraftment and progression. Phenotypic marker analyses demonstrate that STAT1 ${ }^{--}$ mammary tumors arise from luminal epithelial cells, but not myoepithelial cells. In addition, the molecular signature of the $\mathrm{STAT}^{-1}$ mammary tumors overlaps closely to that of human luminal breast cancers. Finally, introduction of wildtype STAT1, but not a STAT1 mutant lacking the critical Tyr701 residue, into STAT1 ${ }^{-1}$ mammary tumor cells results in apoptosis, demonstrating that the tumor suppressor function of STAT1 is cellautonomous and requires its transcriptional activity.

Conclusions: Our findings demonstrate that STAT1 suppresses mammary tumor formation and its expression is frequently lost during breast cancer progression. Spontaneous mammary tumors that develop in STAT1 ${ }^{-1-}$ mice closely recapitulate the progression, ovarian hormone responsiveness, and molecular characteristics of human luminal breast cancer, the most common subtype of human breast neoplasms, and thus represent a valuable platform for testing novel treatments and detection modalities.

\footnotetext{
* Correspondence: schreiber@immunology.wustl.edu

'Department of Pathology and Immunology, Washington University School

of Medicine, 425 S. Euclid Avenue, St. Louis, MO 63110, USA

Full list of author information is available at the end of the article
} 


\section{Introduction}

Estrogen receptor-alpha-positive $\left(E R \alpha^{+}\right)$and progesterone receptor-positive $\left(\mathrm{PR}^{+}\right)$breast cancer account for approximately $60 \%$ to $70 \%$ of the breast cancer cases diagnosed in humans [1,2]. The majority of these tumors exhibit a molecular signature that is characteristic of the luminal subtype [3]. The standard of care for luminal breast cancer is either to inhibit ER $\alpha$ signaling using selective ER modulators or to deprive the tumors of estradiol (E2) by ovarian ablation or aromatase inhibition [4]. Despite the advances in the treatment of luminal breast cancers, progress has been hampered by a significant deficit in murine models that fully reproduce the hormonal responsiveness and dependency of human $\mathrm{ER}^{+} / \mathrm{PR}^{+}$breast cancers [5-8] and that can be used to develop better methods to follow the disease after treatment.

STAT1 is a transcription factor that plays a critical role in interferon (IFN) signaling [9]. Cells lacking STAT 1 respond aberrantly to IFN $\alpha / \beta$ and IFN $\gamma$, and $\mathrm{STAT}^{-1-}$ mice display immune defects rendering them highly susceptible to infection $[10,11]$ and tumor development $[12,13]$. The latter finding shows that STAT1 is important in manifesting the IFN-dependent, cell-extrinsic tumor suppressor actions of immunity (that is, the elimination phase of cancer immunoediting [14]). Other studies have also suggested that STAT1 can function as a cell-intrinsic tumor suppressor by maintaining basal expression levels of caspases [15], upregulating p2 $7^{\text {Kip1 }}$ expression $[16,17]$, or interacting with p53 or BRCA1 [18-20]. However, these latter studies were conducted mostly with cell lines in vitro and have not been validated by in vivo approaches. Most recently, in vivo studies indicated that STAT1 could suppress tumor development in the ErbB2/Neu-driven mammary tumor models [21,22], although its action in other types of mammary tumors remains undefined. Paradoxically, others have proposed that STAT1 can facilitate tumor outgrowth since elevated levels of STAT1 in melanoma cell lines result in their acquisition of resistance to radiation or chemotherapy [23,24]. This apparent paradox has also been observed in biopsies of human breast cancers $[25,26]$. However, it remains unclear whether the altered STAT1 levels were present in the breast cancer cells themselves or in stromal cells. Thus, the physiological role of STAT1 during cancer development remains poorly understood and may be contextdependent.

Here, we show that STAT1 expression is lost or significantly diminished in the neoplastic cells of a subset of human patients with $\mathrm{ER}^{+} / \mathrm{PR}^{+}$breast cancer relative to normal breast epithelium, suggesting that downregulation of STAT1 is associated with tumor progression.
To further investigate this observation, we followed female mice lacking STAT1 longitudinally and found that they spontaneously develop $E R \alpha^{+} / \mathrm{PR}^{+}$, hormoneresponsive mammary gland cancers of the luminal subtype, thus closely recapitulating the characteristics of human $\mathrm{ER}^{+} / \mathrm{PR}^{+}$luminal breast cancers.

\section{Materials and methods}

\section{Immunohistochemistry on human breast cancer samples}

Formalin-fixed paraffin-embedded tissue blocks were retrieved from the archive of the Department of Pathology in Spedali Civili di Brescia, Brescia, Italy. This retrospective study was conducted in compliance with the Declaration of Helsinki and with policies approved by the Ethics Board of Spedali Civili di Brescia. For this largescale retrospective and exclusively observational study on archival materials, patient consent was not needed, as established by Italian regulations (Delibera del garante $\mathrm{n}$. 52 del 24/7/2008 and DL 193/2003). The cohort consisted of 161 primary breast carcinomas selected from a series of routinely examined cases collected between 2006 and 2008, adjacent normal breast tissues from 11 patients with cancer, and normal breast tissues from five healthy individuals (tissues kindly provided by Monica Guaragni, Clinica S. Anna, Brescia, Italy). Breast carcinoma samples were characterized on the basis of histology, ER $\alpha$ (clone SP1; Thermo Fisher Scientific, Waltham, MA, USA) and PR (clone PgR 636; Dako, Glostrup, Denmark) expression, and HER2 amplification by immunohistochemistry (Herceptest; Dako) and fluorescence in situ hybridization (PathVision HER-2 DNA probe kit; Abbott Laboratories, Abbott Park, IL, USA) (summarized in Table 1). STAT1 protein expression was evaluated on four-micron $(4-\mu \mathrm{m})$ tissue sections by using a rabbit polyclonal antibody against STAT1 (sc-346, 1:400; Santa Cruz Biotechnology, Inc., Santa Cruz, CA, USA). Antigen retrieval was performed by microwaving in citrate buffer (pH 6.0). Positive signal was revealed by the Super Sensitive polymer-horseradish peroxidase immunohistochemistry detection system in accordance with the instructions of the manufacturer (BioGenex, San Ramon, CA, USA). Mouse spleens obtained from WT and $\mathrm{STAT}^{-1-}$ mice were used as positive and negative controls, respectively, to confirm the specificity of the STAT1 antibody (Figure 1A). STAT1 expression of the human normal breast tissues and breast tumor samples was assessed according to the percentage of STAT $1^{+}$ tumor or stromal cells (percentage score: $1=$ fewer than $5 \%$ of positive cells; $2=5 \%$ to $25 \%$ of positive cells; $3=$ $25 \%$ to $75 \%$ of positive cells; and $4=$ greater than $75 \%$ of positive cells) and to the intensity of the staining (intensity score: 1 = low; 2 = intermediate, and $3=$ high) (Table 1 and Figure 1B), similar to the determination of ER $\alpha$ 
Table 1 Clinicopathological characteristics of the human patients with breast cancer in this study with STAT1 staining results

\begin{tabular}{|c|c|c|c|c|}
\hline \multirow[b]{2}{*}{ Characteristics } & \multicolumn{3}{|c|}{ Number (percentage) } & \multirow[b]{2}{*}{$P$ value } \\
\hline & $\begin{array}{l}\text { All cases } \\
(n=161)\end{array}$ & $\begin{array}{c}\mathrm{ER}^{-} \\
(n=78)\end{array}$ & $\begin{array}{c}\mathrm{ER}^{+} \\
(n=83)\end{array}$ & \\
\hline \multicolumn{5}{|l|}{ PR expression } \\
\hline Negative & $95(59 \%)$ & $78(100 \%)$ & $7(8 \%)$ & \multirow[t]{2}{*}{$2.91 \times 10^{-38 a}$} \\
\hline Positive & $76(47 \%)$ & $0(0 \%)$ & $76(92 \%)$ & \\
\hline \multicolumn{5}{|l|}{ HER2 IHC or FISH } \\
\hline Negative & $129(80 \%)$ & $46(59 \%)$ & $83(100 \%)$ & \multirow[t]{2}{*}{$1.35 \times 10^{-12 a}$} \\
\hline Positive & $32(20 \%)$ & $32(41 \%)$ & $0(0 \%)$ & \\
\hline \multicolumn{5}{|l|}{ Histology group ${ }^{b}$} \\
\hline A & $6(4 \%)$ & $2(3 \%)$ & $4(5 \%)$ & \multirow{4}{*}{$0.2512^{\mathrm{a}}$} \\
\hline B & $138(85 \%)$ & $71(91 \%)$ & $67(81 \%)$ & \\
\hline C & $16(10 \%)$ & $5(6 \%)$ & $11(13 \%)$ & \\
\hline $\mathrm{D}$ & $1(1 \%)$ & $0(0 \%)$ & $1(1 \%)$ & \\
\hline \multicolumn{5}{|c|}{ Percentage of STAT1 ${ }^{+}$neoplastic cells (percentage score) } \\
\hline$<5 \%$ & $17(11 \%)$ & $7(9 \%)$ & $10(12 \%)$ & \multirow{4}{*}{$0.91^{\mathrm{c}}$} \\
\hline $5 \%-25 \%$ & $20(12 \%)$ & $10(13 \%)$ & $10(12 \%)$ & \\
\hline $26 \%-75 \%$ & $65(40 \%)$ & $33(42 \%)$ & $32(39 \%)$ & \\
\hline$>75 \%$ & $59(37 \%)$ & $28(36 \%)$ & $31(37 \%)$ & \\
\hline \multicolumn{5}{|c|}{ Percentage of STAT1 ${ }^{+}$stromal cells (percentage score) } \\
\hline$<5 \%$ & $0(0 \%)$ & $0(0 \%)$ & $0(0 \%)$ & \multirow{4}{*}{$0.006^{\mathrm{a}}$} \\
\hline $5 \%-25 \%$ & $16(10 \%)$ & $2(3 \%)$ & $14(17 \%)$ & \\
\hline $26 \%-75 \%$ & $54(34 \%)$ & $26(33 \%)$ & $28(34 \%)$ & \\
\hline$>75 \%$ & $91(56 \%)$ & $50(64 \%)$ & $41(49 \%)$ & \\
\hline \multicolumn{5}{|c|}{ STAT1 intensity in STAT1 ${ }^{+}$neoplastic cells (intensity score) } \\
\hline Low & $54(34 \%)$ & $17(22 \%)$ & $37(45 \%)$ & \multirow{3}{*}{$0.0042^{c}$} \\
\hline Intermediate & $60(37 \%)$ & $31(40 \%)$ & $29(35 \%)$ & \\
\hline High & $47(29 \%)$ & $30(38 \%)$ & $17(20 \%)$ & \\
\hline \multicolumn{5}{|c|}{ STAT1 intensity in STAT1 ${ }^{+}$stromal cells (intensity score) } \\
\hline Low & $2(1 \%)$ & $0(0 \%)$ & $2(2 \%)$ & \multirow{3}{*}{$0.0027^{\mathrm{a}}$} \\
\hline Intermediate & $18(11 \%)$ & $3(4 \%)$ & $15(18 \%)$ & \\
\hline High & $141(88 \%)$ & 75 (96\%) & $66(80 \%)$ & \\
\hline
\end{tabular}

${ }^{\mathrm{a}}$ Fisher exact test. ${ }^{\mathrm{b}}$ Histology group A: ductal carcinoma in situ with minor areas of invasive ductal carcinoma; group B: invasive ductal carcinoma; group C: lobular carcinomas; group D: mixed ductal and lobular carcinomas. 'Chi-squared test. ER, estrogen receptor; FISH, fluoresence in situ hybridization; HER2, human epidermal growth factor receptor 2; IHC, immunohistochemistry; PR, progesterone receptor.

expression by using the Allred score [27]. The percentage score was then added to the intensity score to produce the final STAT1 score.

\section{Mice}

129S6/SvEvTac-Stat1 ${ }^{\text {tm1Rds }}$ (referred to here as STAT1deficient, or STAT $1^{-/-}$), 129S6/SvEvTac-Stat $1^{\text {tm1Rds }}-$ Rag2 tm1Fwa (referred to here as STAT1 ${ }^{-/-} \times \mathrm{RAG}^{-/-}$), and B6.129S-Stat1 ${ }^{\text {tm1Dlv }}$ (referred to here as STAT1-null, or $\mathrm{S} 1 \mathrm{~N})$ mice were generated and previously characterized in our laboratories $[10,11,13]$. RAG2 $2^{-/}$mice were generated by Frederick Alt [28]. Wild-type (WT) 129S6/SvEv and $\mathrm{STAT}^{-/-}(129 \mathrm{~S} 6 / \mathrm{SvEv})$ mice were purchased from Taconic Farms (Hudson, NY, USA), and STAT1-null mice (mixed C57BL/6-129/SvEv and pure C57BL/6) were maintained and housed in our laboratories. Mice were scored as tumor-bearing when they reached 10 by $10 \mathrm{~mm}$ in size. All animal experiments were carried out in accordance with the guidelines of the American Association for Laboratory Animal Science as an approved protocol by the Animal Studies Committees in both the Washington University School of Medicine and New York University. These experiments were performed in specific pathogen-free facilities that were accredited by the Association for Assessment and Accreditation of Laboratory Animal Care and that were located at the Washington University School of Medicine and New York University School of Medicine.

\section{Cell cultures}

$\mathrm{STAT}^{-1-}$ mammary tumor cell lines, SSM1, SSM2, and SSM3, were originated from three individual STAT1 ${ }^{-/-}$ 
A
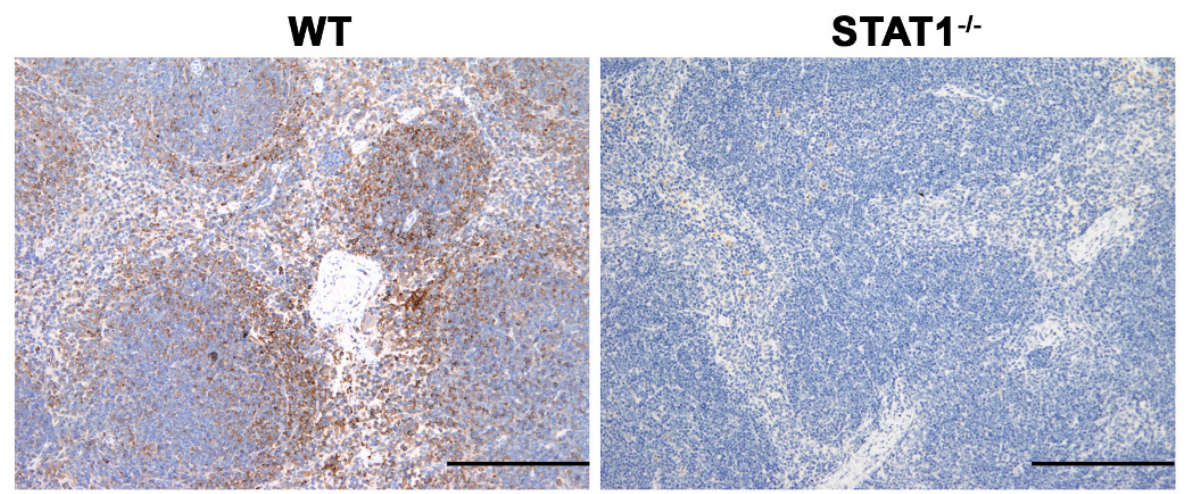

B

low

intermediate

high

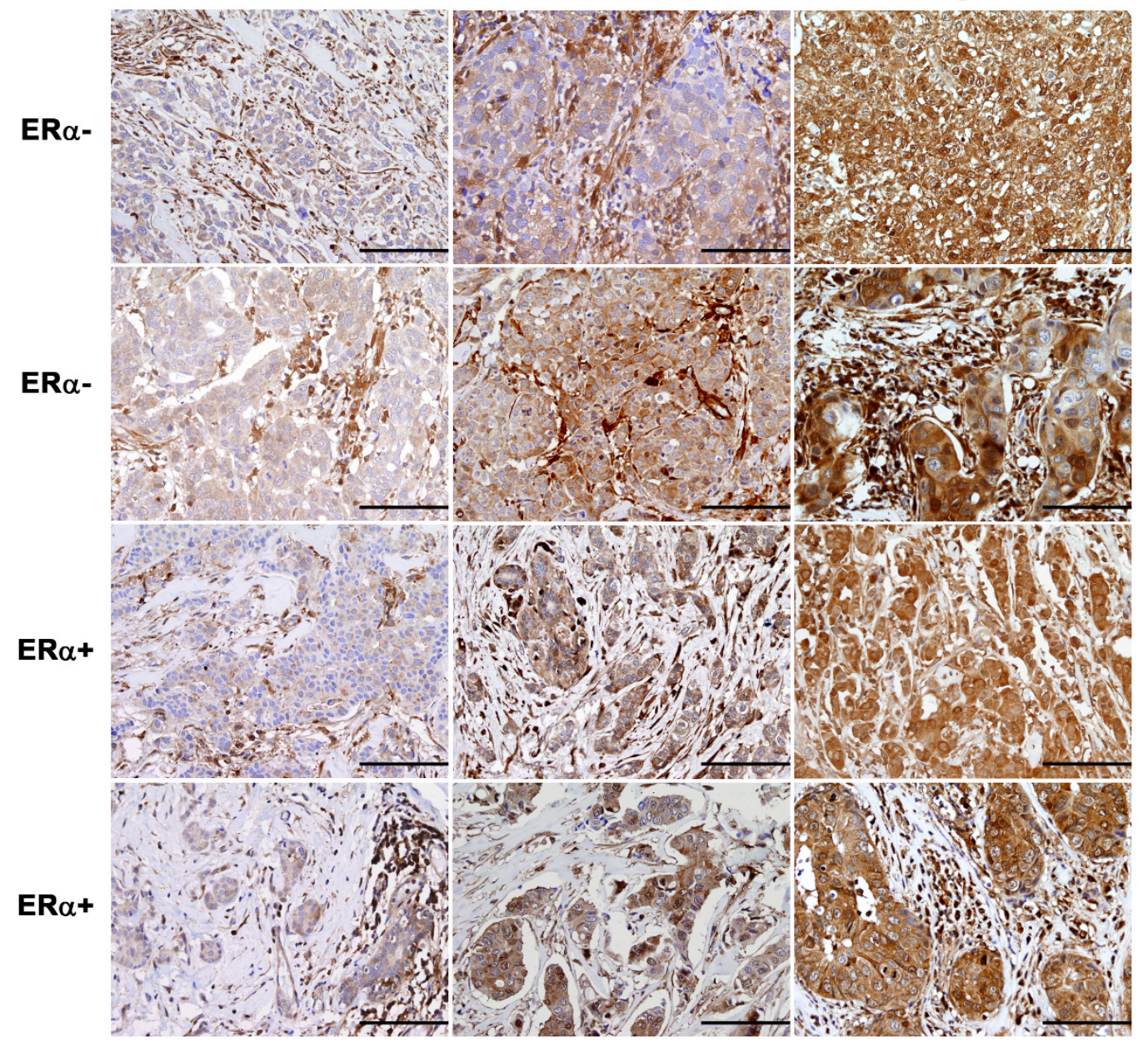

Figure 1 Immunohistochemical analysis of STAT1 expression levels in human breast cancers. (A) Immunohistochemical analysis on wildtype (WT) and STAT1 ${ }^{-1-}$ spleens to confirm the specificity of the antibody against STAT1. Sections of WT or STAT1 ${ }^{-/-}$spleens were stained with a polyclonal rabbit antibody against an epitope in STAT1 which is homologous to both humans and mice. STAT1 reactivity was observed predominantly in the lymphoid cells of the white pulp in WT spleen. However, no appreciable signal was detected in the STAT1 ${ }^{-1}$ spleen. Original magnification, 100x. Scale bars $=200 \mu \mathrm{m}$. (B) The staining intensity of the STAT1 ${ }^{+}$signal was evaluated by using a three-tiered scale (low, intermediate, and high). Low, intermediate, and high STAT1 correspond to the staining intensity scores of 1, 2, and 3, respectively, in Table 2. Six cases of estrogen receptor-alpha-negative $\left(E R \alpha^{-}\right)$and six cases of $E R \alpha^{+}$primary human breast tumors are shown here as representative images. Original magnification, 200x. Scale bars $=100 \mu \mathrm{m}$. 
tumor-bearing mice and were created by mechanical disaggregation of tissue before an overnight incubation with collagenase type IA (200 U/mL; Sigma-Aldrich, St. Louis, MO, USA) and insulin $(10 \mu \mathrm{g} / \mathrm{mL}$; SigmaAldrich) in DMEM/F12/10\% FBS/1\% L-glutamine/1\% penicillin-streptomycin. Clusters of epithelial cells were enriched by sedimentation through five washes of 40 $\mathrm{mL}$ of DMEM/F12/5\% FBS each. Stromal fibroblasts were eliminated by differential trypsinization by using $0.05 \%$ trypsin once a week over the next 2 months. The absence of fibroblasts was determined by immunofluoresence by using an antibody specific for vimentin (sc7557; Santa Cruz Biotechnology, Inc.). The SSM cell lines are maintained in DMEM/F12/10\% FBS/1\% L-glutamine/1\% penicillin-streptomycin/50 $\mu \mathrm{M}$ 2-mercaptoethanol $/ 0.3 \mu \mathrm{M}$ hydrocortisone $/ 5 \mu \mathrm{g} / \mathrm{mL}$ insulin $/ 10$ $\mathrm{ng} / \mathrm{mL}$ transferrin. MCF7 and NMuMG were purchased from American Type Culture Collection (Manassas, VA, USA) and are cultured in DMEM/10\% FBS/1\% L-glutamine/1\% penicillin-streptomycin. The MCF7 cell line is a human $E R \alpha^{+}$breast cancer cell line. NMuMG is an immortalized nontransformed murine mammary gland epithelial cell line.

\section{Immunohistochemistry and immunofluorescence analyses on murine tumor samples}

Tumors were harvested and fixed in 10\% neutral buffered formalin for 1 to 2 days. Paraffin blocks were made, and slides were stained with hematoxylin and eosin (H\&E) for histological examination. To examine the presence of ER $\alpha$ and PR, slides were deparaffinized, serially rehydrated, and stained in accordance with the routine procedures in the Mutant Mouse Pathology Laboratory of the University of California at Davis. For the immunofluoresence assay determining the presence of fibroblasts, SSM tumor cells were plated on coverslips and allowed to attach overnight. Cells were then fixed and permeablized with ice-cold methanol and then acetone for 10 minutes each at $-20^{\circ} \mathrm{C}$. Coverslips were washed extensively with $1 \times$ phosphate-buffered saline (PBS) and blocked with 5.5\% normal donkey serum and $2 \%$ bovine serum albumin in PBS. Cells were incubated with anti-cytokeratin (anti-CK) (wide spectrum) (Z0622, 1:200; Dako) or anti-vimentin (sc-7557, 1:50; Santa Cruz Biotechnology, Inc.) for 1 hour at room temperature. Donkey anti-rabbit conjugated with $\mathrm{Cy} 2$ and donkey anti-goat conjugated with Cy3 (1:200; Jackson ImmunoResearch Laboratories, Inc., West Grove, PA, USA) were used for the detection of $\mathrm{CK}$ and vimentin, respectively. To examine the expression of ER $\alpha$, tumor cells were plated on coverslips, fixed in $4 \%$ paraformaldehyde, and permeablized in $0.5 \%$ Triton X-100. Monoclonal antibody against ER $\alpha$ (6F11, 1:40; Novocastra, now part of Leica, Wetzlar, Germany) and donkey anti-mouse conjugated with Cy3 were used. DAPI (4'-6-diamidino2-phenylindole) was used to identify nuclei in all immunofluoresence assays (Molecular Probes, now part of Life Technologies, Grand Island, NY, USA).

\section{Southern blotting}

Southern blot analysis was performed as described previously [29]. The probe was prepared by digesting a plasmid containing the MMTV long terminal repeat with BamHI (the MMTV-LTR plasmid was a generous gift from Elena Buetti of the Swiss Institute for Experimental Cancer Research in Switzerland) [30].

\section{MTT}

MCF7, SSM1, SSM2, or SSM3 was plated in 96-well plates in phenol red-free media with $10 \%$ charcoal-treated FBS (HyClone, Logan, UT, USA) supplemented with hydrocortisone, insulin, and transferrin and with or without $10 \mathrm{nM} 17-\beta$-estradiol (Sigma-Aldrich). Cell proliferation was determined by using 3-(4,5-dimethyl-2thiazlyl)-2,5-diphenyl-2H-tetrasolium bromide (MTT) assays in accordance with the instructions of the manufacturer (Promega Corporation, Madison, WI, USA).

\section{Western blotting}

SSM1, SSM2, SSM3, and NMuMG cells were lysed in RIPA buffer (R0278; Sigma-Aldrich) with $2 \mathrm{mM}$ sodium vanadate, protease inhibitor cocktail (P8340, 1:500; Sigma-Aldrich), and phosphatase inhibitor cocktail (P5726, 1:100; Sigma-Aldrich). Cleared lysate (200 $\mu \mathrm{g})$ was resolved on SDS-PAGE and transferred onto nitrocellulose membranes. ER $\alpha$ expression was detected by incubating blots with the monoclonal antibody 6F11 against ER $\alpha$ (VP-E613, 1:500; Vector Laboratories, Burlingame, CA, USA). PR expression was examined with a PR antibody against the $C$ terminus of both PR-A and PR-B (sc-538, 1:500; Santa Cruz Biotechnology, Inc.).

\section{Ovariectomy and tumor transplantation}

Female WT or STAT1 ${ }^{-1}$ mice were either sham-operated or ovariectomized at 6 to 8 weeks of age under general anesthesia. Two weeks after the surgery, $10^{5}$ SSM1, SSM2, or SSM3 mammary tumor cells in $10 \mu \mathrm{L}$ were injected into the inguinal fat pads of the mice. Alternatively, tumor fragments of about $1 \mathrm{~mm}$ in size were transplanted into the inguinal fat pads. Tumor growth was monitored by palpation once every 3 to 6 days and measured at two perpendicular diameters. The average of the two perpendicular measurements was plotted. In experiments in which exogenous E2 was supplemented to ovariectomized mice, 60 -day release E2 pellets at $0.5 \mathrm{mg}$ per pellet were used (Innovative Research of America, Sarasota, FL, USA). In the endocrine treatment experiment, $\mathrm{nu} / \mathrm{nu}$ mice or STAT $1^{-/-}$ 
mice were transplanted with $10^{6}$ SSM3 tumor cells or tumor fragments, respectively. When the established tumors reached $5 \mathrm{~mm}$ in diameter, the animals were either sham-operated or ovariectomized. Tumor growth was monitored as described above.

\section{Immunophenotypic analyses on STAT1 ${ }^{-/-}$mammary glands}

Mammary glands were harvested from 10- to 14-monthold STAT1 ${ }^{-1-}$ female mice and digested in collagenase and hyaluronidase solution, as described in [31]. Single-cell suspension was prepared after dissociated tissues were treated with trypsin/DNase for 1 minute and dispase/DNase for 2 minutes and passed through $40-\mu \mathrm{m}$ cell strainers. Cells were first blocked with anti-CD16 and anti-CD32 Fc $\gamma$ receptors and normal rat serum and then stained with anti-TER119-PE/Cy7 (BioLegend, San Diego, CA, USA), anti-CD31-PE/Cy7 (BioLegend), anti-CD45-PE/Cy7 (BioLegend), anti-CD24-APC (BioLegend), or anti-CD49f-biotin (BioLegend) for 20 minutes at $4^{\circ} \mathrm{C}$. Streptavidin-APC/ Cy7 (BioLegend) was added, and cells were incubated for 20 minutes at $4^{\circ} \mathrm{C}$. Stained cells were collected by using an LSRII flow cytometer (BD Biosciences, San Jose, CA, USA). Dead cells were gated out by using DAPI (Invitrogen Corporation). Cells depleted of CD31, CD45, and TER119 were further analyzed on the basis of their CD49f and CD24 surface expression. Myoepithelial cells were defined as CD49f ${ }^{\text {hi }} \mathrm{CD} 24^{\text {int }}$, whereas luminal epithelial cells were CD49f ${ }^{\text {int }} \mathrm{CD} 24^{\text {hi }}$, as established previously [31-33]. Flow cytometry profiles were analyzed by using FloJo software (TreeStar Inc., Ashland, OR, USA).

\section{STAT1 reconstitution}

Retrovirus expressing GFP alone, STAT1.IRES.GFP, and STAT1 mutants Y701F.IRES.GFP and S727A.IRES.GFP was prepared by co-transfecting Phoenix cells with the retrovirus plasmid and pCMV.VSVg by using FuGENE HD (Roche, Basel, Switzerland). Supernatant was harvested 48 and 72 hours after transfection and overlayed on NMuMG, SSM1, SSM2, or SSM3 cells in the presence of $8 \mu \mathrm{g} / \mathrm{mL}$ of polybrene for 6 to 8 hours. Infection was carried out for 2 consecutive days. The infected cells were harvested on day 2 after infection for Western blotting to confirm expression and on day 3 for flow cytometry to quantitate the percentages of cells undergoing early apoptosis. Apoptosis was measured by a flow cytometry-based annexin $\mathrm{V}$-binding assay in accordance with the instructions of the manufacturer (BD Biosciences). Only the early apoptotic cells (annexin $\mathrm{V}$-positive, 7AAD-negative) were analyzed.

\section{Gene expression profiling analysis}

Total RNAs were isolated from normal mammary glands of primary $\mathrm{STAT}^{-1-}$ mammary tumors by using
Trizol in accordance with the procedure of the manufacturer (Invitrogen Corporation). RNA integrity was confirmed by using an Agilent bioanalyzer (Agilent Technologies, Inc., Santa Clara, CA, USA). Labeled target cRNAs were synthesized and hybridized to Affymetrix GeneChip MOE 4302.0 arrays in accordance with the instructions of the manufacturer. Raw data were modeled and normalized by using dChip [34]. Wellannotated mouse and human orthologs were identified by using the Mouse Genome Informatics database [35], and medians were used in cases of redundant probesets. The Herschkowitz data matrix contains 232 human breast cancer datasets and 122 murine datasets from 13 different mammary tumor models, which were analyzed by using 106 intrinsic genes common to the two species [36]. To combine our STAT1 ${ }^{-1-}$ mammary tumor datasets with the Herschkowitz datasets, 96 of the 106 intrinsic genes were used because of platform differences. Gene-wise normalization was carried out separately with each dataset such that each gene has median zero and unit standard deviation. Distance-weighted discrimination (DWD) was used to merge our datasets with the Herschkowitz datasets to eliminate large systematic biases arising from different RNA purification procedures and distinct microarray platforms $[37,38]$. For unsupervised cluster analysis, the average linkage hierarchical clustering algorithm was then applied to the merged datasets by using XCluster [39] with the centered correlation coefficient as the similarity/dissimilarity metric. The gene expression heatmap and dendrogram were generated in Java TreeView [40] to visualize the relationship between the human breast cancer subtypes and murine mammary tumor models according to the gene expression intensities of the 96 genes. Gene expression profiling data have been deposited in the National Center for Biotechnology Information's Gene Expression Omnibus (GEO) under accession number GEO:GSE31942 [41].

\section{sigClust}

sigClust examines the significance of a given clustering by testing the null hypothesis that the datasets are from the same Gaussian distribution [42]. We applied sigClust to five STAT1 ${ }^{-1}$ primary tumor samples and 63 human luminal breast cancer samples by using the 96 -gene intrinsic gene list. The resulting $P$ value is 0.99998 , which indicates that the STAT1 $1^{-1-}$ mammary tumors are highly likely to be in the same cluster with the human luminal breast cancer datasets. In addition, we applied sigClust on the MMTV_Neu and MMTV_PyMT datasets from the Herschkowitz study [36]. To avoid potential bias due to different sample sizes, we drew a set of five samples out of these two sets of data through 200 iterations and implemented the test on the set of five 
samples and the human luminal breast cancer datasets. The average $P$ values were 0.9110 (MMTV_Neu), 0.9630 (MMTV_PyMT), and 0.9665 (both mouse models combined). These results indicate that the STAT1 ${ }^{-1-}$ mammary tumor model exhibits a higher degree of resemblance to human luminal breast cancers at the gene expression level than the MMTV-Neu and MMTV-PyMT models do.

\section{Consensus clustering}

To investigate the stability of clustering between $\mathrm{STAT}^{-/-}$mammary tumors and human luminal breast cancer, consensus clustering, which is a re-samplingbased technique that uses perturbation to simulate a set of new samples from the original merged dataset, was employed [43]. Consensus index on empirical clustering results across all perturbed datasets was then summarized by the normalized proportion of times that two samples were assigned to the same cluster. The underlying assumption is that the induced cluster composition is more trustworthy if the clustering is robust to sampling variability. We re-sampled 1,000 times and considered the number of clusters ranging from two to 15 for assessment. Using the 96-gene intrinsic gene list, we found that the five STAT1 $1^{-1-}$ mammary tumors belong to the same cluster $95 \%$ of the time after 1,000 re-samplings with an interquartile range (IQR) of 0.9128 to 0.9775 (range $=0.8964$ to 1.0 ), which indicates that the $\mathrm{STAT}^{-1-}$ mammary tumors are molecularly homogeneous. The STAT1 ${ }^{-1-}$ mammary tumors and human luminal breast cancers cluster together $62 \%$ out of 1,000 re-samplings with an IQR of 0.57 to 0.67 (range $=0.32$ to 0.78 ). In contrast, the MMTV-Neu and MMTVPyMT mouse models cluster with the human luminal breast cancer datasets only $42 \%$ out of 1,000 re-samplings with an IQR of 0.44 to 0.48 (range $=0.01$ to0.64). These results further demonstrate that the molecular signature of the STAT1 ${ }^{-1-}$ mammary tumors significantly overlaps with that of human luminal breast cancers.

\section{Statistical analyses}

Time to onset was analyzed by the Kaplan-Meier product limit method, which generated the Kaplan-Meier survival curves. $P$ values were reported by log-rank test. All numerical results are presented as mean and standard error of mean and represent data from a minimum of three independent experiments unless otherwise stated. Tumor growth curves were analyzed by a distribution-free test [44]. The unpaired $t$ test for two independent samples was used to determine the statistical significance between the experimental groups and control groups. Wilcoxon signed rank test was used to compare STAT1 intensity levels in tumor samples and adjacent normal breast tissues. Association between clinicopathological characteristics and ER $\alpha$ status was tested by chi-squared test or Fisher exact test, whichever was appropriate. All tests were two-sided, and a $P$ value of not more than 0.05 was considered significant. GraphPad Prism (GraphPad Software, Inc., La Jolla, CA, USA), SAS 9.2 (SAS Institute Inc., Cary, NC, USA), and R 2.11.1 [45] were used for all statistical analyses.

\section{Results}

A subset of human breast cancers display reduced STAT1 expression in neoplastic cells

To explore the role of STAT1 in breast tumor development, the relative cellular levels of STAT1 protein were immunohistochemically assessed in a cohort of 161 primary breast cancer samples (78 ER $\alpha^{-}$and $83 \mathrm{ER}^{+}$ cases) (Table 1) by using a STAT1-specific polyclonal IgG antibody that recognizes a STAT1 epitope shared by the human and mouse proteins (Figure 1A). Normal breast tissues from 11 patients with cancer and five healthy individuals were used as nontransformed controls (Table 2). STAT1 expression in epithelial cells and infiltrating stromal cells was quantified on the basis of the percentage of STAT $1^{+}$cells (percentage score) and the intensity of the positive signal by using a threetiered scale (intensity score) (Figure 1B and Materials and methods).

In normal human breast tissue from healthy individuals, STAT1 was detected in the cytoplasm of luminal epithelial cells, in the nuclei of the spindle cells in the surrounding stroma, and sporadically in myoepithelial cells (Figure 2A). In contrast, STAT1 expression was highly variable among tumor samples (Figures 1B, 2B, $\mathrm{D}$, and $2 \mathrm{~F})$, consistent with previous reports $[46,47]$. Specifically, in $11 \%$ of cases (17 out of 161 ), STAT1 expression was detectable in less than $5 \%$ of the neoplastic cells, whereas in $37 \%$ of cases (59 out of 161), more than $75 \%$ of the tumor cells expressed STAT1 (percentage score in Table 1). The remaining 52\% of cases displayed an intermediate phenotype in which STAT1 staining was observed in $5 \%$ to $75 \%$ of the neoplastic cells. In addition to documenting the percentage of STAT $1^{+}$cells, we recorded the relative intensity of the positive signal (intensity score). Thirty-four percent of the tumor cases (54 out of 161) exhibited low STAT1 staining in the neoplastic cells, whereas $37 \%$ and $29 \%$ showed intermediate and high staining, respectively (Table 1). Although the percentages of STAT $1^{+}$neoplastic cells in $E R \alpha^{-}$and $E R \alpha^{+}$tumors were comparable (percentage score in Table 1), the intensity of the staining was significantly lower in $E R \alpha^{+}$breast cancers than in $E R \alpha^{-}$breast cancers (intensity score in Table 1 and summarized in Figure 2G). Specifically, $45 \%$ of the $E R \alpha^{+}$ tumors exhibited low levels of STAT1 staining in neoplastic cells, in contrast to $22 \%$ of the $E R \alpha^{-}$cases, 
Table 2 Summary of the STAT1 staining results on normal breast tissues and paired breast tumors

\begin{tabular}{|c|c|c|c|c|c|c|c|}
\hline \multirow[b]{2}{*}{ Case } & \multirow[b]{2}{*}{$E R \alpha^{a}$} & \multicolumn{3}{|c|}{ Normal breast tissues } & \multicolumn{3}{|c|}{ Breast tumors } \\
\hline & & $\begin{array}{l}\text { Percentage of STAT1 } 1^{+} \\
\text {epithelial cells }{ }^{\mathbf{b}}\end{array}$ & $\begin{array}{l}\text { STAT1 staining } \\
\text { intensity }^{c}\end{array}$ & $\begin{array}{l}\text { STAT1 } \\
\text { score }^{\text {d }}\end{array}$ & $\begin{array}{c}\text { Percentage of STAT1 }{ }^{+} \\
\text {neoplastic cells }\end{array}$ & $\begin{array}{l}\text { STAT1 staining } \\
\text { intensityc }^{c}\end{array}$ & $\begin{array}{l}\text { STAT1 } \\
\text { score }^{d}\end{array}$ \\
\hline HN1 & NA & 4 & 2 & 6 & NA & NA & NA \\
\hline HN2 & NA & 4 & 1 & 5 & NA & NA & NA \\
\hline HN3 & NA & 4 & 2 & 6 & NA & NA & NA \\
\hline $\mathrm{HN} 4$ & NA & 3 & 1 & 4 & NA & NA & NA \\
\hline HN5 & NA & 4 & 2 & 6 & NA & NA & NA \\
\hline 87 & + & 4 & 2 & 6 & 1 & 1 & 2 \\
\hline 160 & + & 4 & 2 & 6 & 1 & 1 & 2 \\
\hline 84 & + & 4 & 2 & 6 & 1 & 1 & 2 \\
\hline 147 & + & 4 & 2 & 6 & 1 & 1 & 2 \\
\hline 80 & + & 4 & 2 & 6 & 1 & 1 & 2 \\
\hline 115 & + & 4 & 2 & 6 & 1 & 1 & 2 \\
\hline 161 & + & 3 & 2 & 5 & 1 & 1 & 2 \\
\hline 58 & - & 3 & 1 & 4 & 1 & 1 & 2 \\
\hline 20 & - & 3 & 1 & 4 & 1 & 1 & 2 \\
\hline 53 & & 4 & 2 & 6 & 1 & 2 & 3 \\
\hline 47 & - & 4 & 2 & 6 & 1 & 2 & 3 \\
\hline
\end{tabular}

Normal breast tissues from healthy individuals: HN1, HN2, HN3, HN4, and HN5. Paired tumor samples with adjacent normal breast tissues: case 87, 160, 84, 147, $80,115,161,58,20,53$, and 47 . ' ${ }^{a}$ Estrogen receptor-alpha (ER $\alpha$ ) expression in breast tumors. ${ }^{b}$ Percentage score: $1,<5 \% ; 2,5 \%-25 \% ; 3,26 \%-75 \% ; 4,>75 \%$.

'Intensity score: 1 = low, 2 = intermediate, 3 = high. ${ }^{d}$ STAT1 score = percentage score + intensity score. +, positive; -, negative; NA, not applicable.

demonstrating that reduced STAT1 expression is associated with $\mathrm{ER} \alpha^{+}$tumors (Table 1 and Figure 2G). A similar trend was observed in the stroma between $\mathrm{ER} \alpha^{-}$ and $\mathrm{ER}^{+}$cases (Figure 2G). However, since STAT1 was universally elevated in stromal cells compared with neoplastic cells within the same tumors (Figure 2D, F, and quantified in Figure 2G), the difference in stromal STAT1 intensity between $\mathrm{ER} \alpha^{-}$and $\mathrm{ER}^{+}$cases is unlikely to be functionally meaningful. These findings thus indicate that STAT1 expression is differentially regulated in epithelial versus stromal compartments.

In contrast to the observation that lower STAT1 expression levels were associated with $\mathrm{ER} \alpha^{+}$breast cancers versus $\mathrm{ER} \alpha^{-}$cancers, there was no significant association between low STAT1 expression and HER2 status (Table 3). HER $2^{-}$and HER2 ${ }^{+}$breast cancers displayed similar percentages of $\mathrm{STAT}^{+}$cells and levels of STAT1 intensity in the stromal and neoplastic compartments (Table 3). When these data are taken together, the lowest level of STAT1 expression is preferentially associated with the $\mathrm{ER} \alpha^{+}$breast cancer subtype.

Since STAT1 is uniformly expressed in the luminal epithelial cells of breast tissues from normal healthy individuals, the observation that a large subset of breast cancer cases exhibit low levels of STAT1 expression suggests that STAT1 may be downregulated specifically in the neoplastic cells. To further investigate this possibility, STAT1 expression was also assessed in morphologically normal breast tissues of patients with breast cancer. In all of the 11 STAT1-low breast cancer cases in which adjacent normal breast tissues were available, normal breast tissues had significantly more STAT $1^{+}$ epithelial cells and exhibited stronger staining intensity than matched tumor tissues (Figure 2C-F and Table 2). This resulted in an overall higher STAT1 score in normal epithelial cells than in breast tumor cells (Figure $2 \mathrm{H})$. These findings thus demonstrate that STAT1 expression is dramatically diminished or lost in a significant proportion of breast cancer cells during tumor progression.

\section{$\mathrm{STAT}^{-/-}$mice are highly susceptible to mammary tumor formation}

The findings that diminished STAT1 expression is associated with breast cancer progression prompted us to investigate whether loss of STAT1 was a cause, not merely a consequence, of mammary tumorigenesis. We monitored WT and STAT1 ${ }^{-/-} 129 \mathrm{~S} 6 / \mathrm{SvEv}$-strain female mice for tumor development and found that 65\% (15 out of 23) of the STAT1 $1^{-/-}$mice developed spontaneous mammary adenocarcinomas (median tumor onset of 23 months) but that none of the WT mice developed the disease (Figure 3A). In agreement with our previous report [13], we observed mammary tumor development in a larger cohort of STAT1 ${ }^{-1-} \times \mathrm{RAG}^{-/-}$female mice in similar disease incidences (Figure 3A). STAT1 ${ }^{-1-}$ mice developed mammary tumors only, whereas $\mathrm{STAT}^{-1-} \times$ $\mathrm{RAG}^{-/-}$mice developed mammary and intestinal tumors. Mice lacking RAG2 alone did not develop mammary tumors (Figure $3 \mathrm{~A}$ ), demonstrating that this 


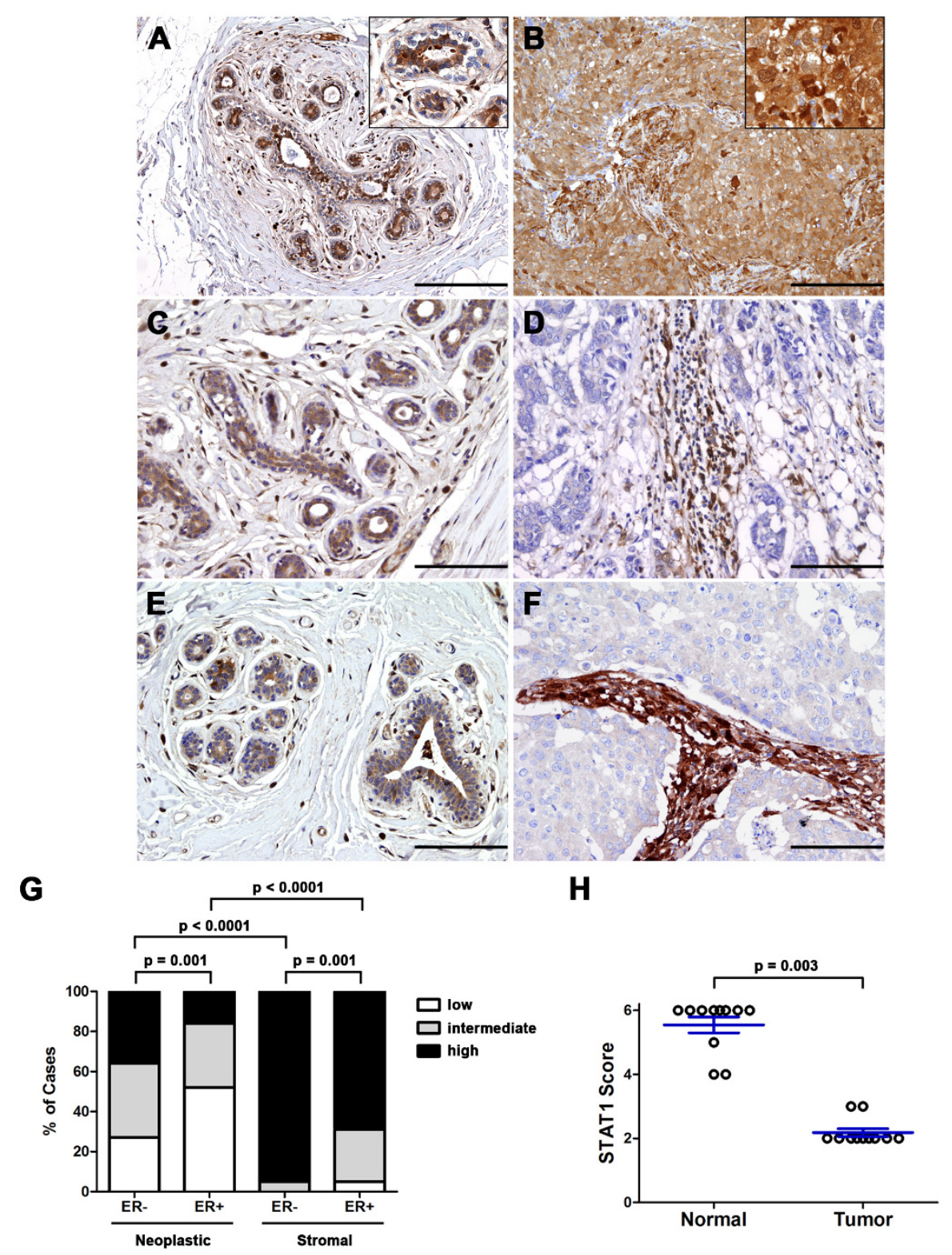

Figure 2 Selective downregulation of STAT1 expression in the neoplastic cells of human breast tumors. (A) Representative image of STAT1 staining on normal breast tissues of healthy individuals $(n=5)$ shows STAT1 expression in luminal epithelial cells and stromal cells and occasionally in myoepithelial cells. Original magnification, 100x. Scale bar $=200 \mu \mathrm{m}$. Inset, 400x. (B) Representative image of a breast tumor case with high levels of STAT1 expression in both the epithelial and stromal compartments. Original magnification, 200x. Scale bar $=100 \mu \mathrm{m}$. Inset, 400x. (C-F) Representative images of paired adjacent normal breast tissues (left) with breast tumors (right; $n=11$ ). Morphologically normal breast tissues from patients with breast cancer display a STAT1 expression pattern that is similar to that in normal breasts from healthy individuals $(C, E)$. Panel $(C)$ is the paired normal tissue of the tumor in panel (D) (case 87), whereas panel $(E)$ is the paired normal tissue of the tumor in panel (F) (case 58). The epithelial tumor cells of the representative estrogen receptor-alpha-positive (ER $\left.\alpha^{+}\right)(D)$ and $E R \alpha^{-}(F)$ breast cancers were devoid of STAT1 expression, whereas STAT1 level remained high in the tumor stroma. Original magnification, 200x. Scale bars = $100 \mu \mathrm{m}$. (G) Intensity scores of the neoplastic and stromal cells of all cases $(n=161)$ are plotted. Reduced STAT1 staining intensity was preferentially associated with $E R \alpha^{+}$human breast cancers relative to $E R \alpha^{-}$breast cancers in both the neoplastic and stromal compartments $(P=$ 0.001, unpaired $t$ test). Stromal cells had an overall higher STAT1 expression level than the neoplastic cells of the same tumors $(P<0.0001$, Wilcoxon signed rank test). (H) Breast tumors exhibited significant reduction in STAT1 score in comparison with matched normal breast tissues $(n=11)\left(P=0.003\right.$, Wilcoxon signed rank test). STAT1 score is the sum of the score representing the percentages of STAT1 ${ }^{+}$cells (percentage score) and that representing the STAT1 staining intensity (intensity score). 
Table 3 Summary of the STAT1 staining results in the estrogen receptor-negative human breast cancer cohort stratified by HER2 status

\begin{tabular}{|c|c|c|c|c|}
\hline \multirow[b]{2}{*}{ Characteristics } & \multicolumn{3}{|c|}{ Number (percentage) } & \multirow[b]{2}{*}{$P$ value } \\
\hline & $\begin{array}{l}\text { All ER cases } \\
\quad(n=78)\end{array}$ & $\begin{array}{l}\text { HER2 }^{-} \\
(n=46)\end{array}$ & $\begin{array}{l}\text { HER2 }^{+} \\
(n=32)\end{array}$ & \\
\hline \multicolumn{5}{|c|}{ Percentage of STAT1 ${ }^{+}$neoplastic cells (percentage score) } \\
\hline$<5 \%$ & $7(9 \%)$ & $4(9 \%)$ & $3(10 \%)$ & \\
\hline $5 \%-25 \%$ & $10(13 \%)$ & $8(17 \%)$ & $2(6 \%)$ & $0.14^{\mathrm{a}}$ \\
\hline $26 \%-75 \%$ & $33(42 \%)$ & $22(48 \%)$ & $11(34 \%)$ & \\
\hline$>75 \%$ & $28(36 \%)$ & $12(26 \%)$ & $16(50 \%)$ & \\
\hline \multicolumn{5}{|c|}{ Percentage of STAT1 ${ }^{+}$stromal cells (percentage score) } \\
\hline$<5 \%$ & $0(0 \%)$ & $0(0 \%)$ & $0(0 \%)$ & \\
\hline $5 \%-25 \%$ & $2(3 \%)$ & $2(4 \%)$ & $0(0 \%)$ & $0.2^{\mathrm{a}}$ \\
\hline $26 \%-75 \%$ & $26(33 \%)$ & $18(39 \%)$ & $8(25 \%)$ & \\
\hline$>75 \%$ & $50(64 \%)$ & $26(57 \%)$ & $24(75 \%)$ & \\
\hline \multicolumn{5}{|c|}{ STAT1 intensity in STAT1 ${ }^{+}$neoplastic cells (intensity score) } \\
\hline Low & $17(22 \%)$ & $10(22 \%)$ & $7(22 \%)$ & \\
\hline Intermediate & $31(40 \%)$ & $19(41 \%)$ & $12(38 \%)$ & $0.96^{\mathrm{b}}$ \\
\hline High & $30(38 \%)$ & 17 (37\%) & $13(40 \%)$ & \\
\hline \multicolumn{5}{|c|}{ STAT1 intensity in STAT1 ${ }^{+}$stromal cells (intensity score) } \\
\hline Low & $0(0 \%)$ & $0(0 \%)$ & $0(0 \%)$ & \\
\hline Intermediate & $3(4 \%)$ & $0(0 \%)$ & $3(10 \%)$ & $0.07^{\mathrm{a}}$ \\
\hline High & $75(96 \%)$ & $46(100 \%)$ & $29(90 \%)$ & \\
\hline
\end{tabular}

${ }^{\mathrm{a}}$ Fisher exact test. ${ }^{\mathrm{b}} \mathrm{Chi}$-squared test. ER, estrogen receptor; HER2, human epidermal growth factor receptor 2.

phenotype is specifically associated with STAT1 deficiency. Cells from our STAT1 1 mice express low levels of a nonfunctional truncated STAT1 protein and are incapable of responding to IFN either in vitro or in vivo $[10,48]$. Nevertheless, by examining STAT1-null (S1N) mice generated by using a different targeting strategy and different embryonic stem cells that were maintained on a mixed C57BL/6-129/SvEv background, we ruled out the possibility that this truncated protein is involved in disease development [11]. Female S1N mice also developed spontaneous mammary tumors with a median tumor onset of 14.5 months (Figure 3A). Although the S1N mice exhibited a shorter latency than the 129S6/ SvEv STAT1 ${ }^{-1-}$ mice, the penetrance of the two cohorts was indistinguishable and the difference in the overall tumor incidences was not statistically significant $(P=$ 0.26). These results demonstrate the generality of the phenotype to mice lacking functional STAT1, regardless of targeting strategy or mouse strain. STAT1 $1^{-/-}$mice that were sterilely re-derived and housed exclusively in a
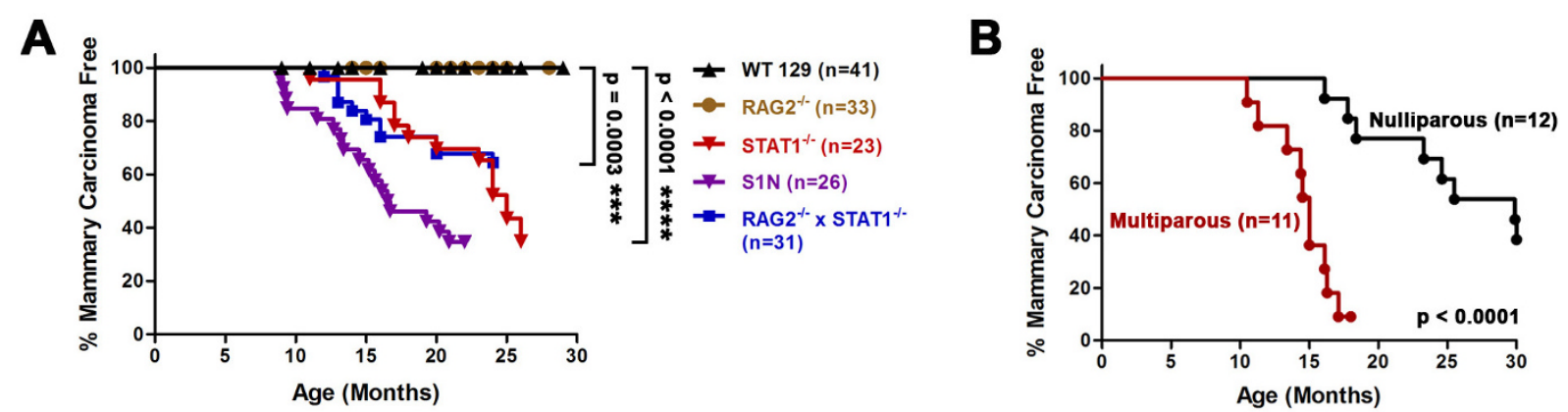

Figure 3 Spontaneous development of mammary gland adenocarcinomas in STAT1 deficient (STAT1 ${ }^{-1}$ ), STAT1 null (S1N), and STAT1 ${ }^{-1-}$ $\times \mathrm{RAG2}^{-1-}$ female mice. (A) STAT1 $1^{---}\left(n=23\right.$, inverted red triangles), S1N $\left(n=26\right.$, inverted purple triangles), and STAT1 $1^{-1-} \times$ RAG $^{-1-}(n=31$, blue squares) mice succumbed to mammary tumors, whereas none of the age-matched wild-type (WT) 129S6/SvEv ( $n=41$, black triangles) or RAG2 ${ }^{-1}$ ( $n=33$, yellow circles) mice developed the disease. $P$ values were obtained with log-rank test by comparing STAT1 ${ }^{-1} \times$ RAG $^{-1}$ with WT mice $\left({ }^{* * *} P=0.0003\right)$ and $\mathrm{STAT1}^{--}$or S1N with WT mice $\left.{ }^{* * * *} P<0.0001\right)$. Curves between STAT1 ${ }^{-1}$ and S1N mice are not different to a statistically significant degree $(P=0.24)$. (B) Multiparous STAT1 ${ }^{--}$mice $(n=11$, red) developed mammary tumors at a higher frequency and with shorter latency than nulliparous STAT1 ${ }^{-1}$ mice $(n=12$, black) $(P<0.0001)$. 
commercial gnotobiotic facility also developed mammary tumors, a result suggesting that the disease was not of infectious origin. This conclusion was substantiated by viral microarrays [49] that failed to detect either known or novel viruses in mammary tumors or other tissues of STAT1 ${ }^{-1-}$ mice and by the lack of evidence for translocation and additional chromosomal integration of endogenous mammary tumor proviruses in these tumors (Figure S1 in Additional file 1).

Since tumor development did not reach a complete penetrance in the STAT1 ${ }^{-1-}$ and S1N mice, we examined whether parity might influence tumorigenesis. Strikingly, multiparous STAT1 ${ }^{-1-}$ mice developed mammary tumors sooner and at a higher frequency than nulliparous $\mathrm{STAT}^{-1-}$ mice (Figure 3B). Specifically, multiparous mice had a median tumor onset of 14.8 months versus 24.6 months of nulliparous mice. Most importantly, the incidence of tumor development was $91 \%$ (10 out of 11 ) in mice that had undergone multiple rounds of pregnancy and lactation compared with $62 \%$ of nulliparous mice. Taken together, these data suggest that pregnancy-associated hormones might accelerate mammary tumor formation in $\mathrm{STAT1}^{-/-}$mice.

\section{$\mathrm{STAT1}^{-/-}$mammary tumors display homogeneous expression of estrogen receptor-alpha}

Examination of whole mounts of mammary gland tissues from 12- to 24-month-old female STAT1 ${ }^{-1-}$ mice without palpable masses revealed focal atypias in about $50 \%$ of the cohort $(n=19)$ (Figure 4A, B). This abnormality was not observed in mammary glands of agematched WT female mice $(n=12)$. The early lesions in $\mathrm{STAT}^{-1-}$ mammary glands varied from distended ducts to small cystically dilated clusters of alveoli (Figure 4B). Analysis of the H\&E-stained tissue sections revealed that these abnormal foci contained atypical cells fulfilling the criteria for mammary intraepithelial neoplasia (MIN) (Figure 4C, D) [50]. Surprisingly, atypical nuclei in MIN lesions stained positively for ER $\alpha$ and PR (Figure $4 \mathrm{E}-\mathrm{H})$. Similar analyses of overt tumors revealed the presence of solid nests of neoplastic $\mathrm{ER}^{+}$or $\mathrm{PR}^{+}$cells with frequent central necroses (Figure 4I-N). Over $90 \%$ of all tumor cells expressed ER $\alpha$ (Figure 4K, L). Some tumors had invasive nests of neoplastic cells with areas of fibrosis and inflammation (Figure 4I, J). All primary $\mathrm{STAT}^{-1-}$ mammary tumors examined, regardless of parity, showed similar histopathological characteristics and patterns of hormone receptor expression. None of the primary tumors stained positively for HER2 (data not shown). Thus, mammary tumors in STAT1 ${ }^{-1-}$ mice progress developmentally from intraepithelial neoplasia to carcinoma in a manner that is remarkably similar to the progression from ductal carcinoma in situ to invasive ductal carcinoma seen in the human disease [51]. Since spontaneous $\mathrm{ER} \alpha^{+} / \mathrm{PR}^{+}$mammary tumors are rarely observed in mice, our findings also suggested that $\mathrm{STAT}^{-1-}$ mice may represent a relatively novel model for human $\mathrm{ER}^{+} / \mathrm{PR}^{+}$luminal breast cancer.

\section{Ovarian hormone dependency of STAT1 ${ }^{-/-}$mammary tumor cells}

To facilitate biological and biochemical characterization of the STAT $1^{-/-}$mammary tumors, three tumor cell lines were established and designated spontaneous $\mathrm{STAT}^{-/-}$mammary (SSM) epithelial tumor cell lines (SSM1, SSM2, and SSM3). All expressed CK but not vimentin in vitro, documenting their epithelial origin (Figure S2 in Additional file 2). SSM2 and SSM3 expressed nuclear $E R \alpha$, which is similar to the human $\mathrm{ER} \alpha^{+}$breast cancer cell line, MCF7 (Figure 5A). SSM2 and SSM3 also expressed the two PR isoforms, PR-A and PR-B (Figure $5 \mathrm{C}$ ), suggesting that $\mathrm{ER} \alpha$ is functional in these cells. In contrast, SSM1 expressed a very low level of ER $\alpha$ (Figure $5 \mathrm{~B}$ ) and no detectable PR-A/PR-B expression (Figure $5 \mathrm{C}$ ), indicating a lack of ER $\alpha$ signaling in the SSM1 cells. Whereas SSM2 and SSM3 required the presence of estrogen to proliferate in vitro, SSM1 did not (Figure 6A). Finally, when transplanted into the fat pads of WT or STAT $1^{-1-}$ mice, SSM2 and SSM3 grew only in recipients with intact ovaries or in ovariectomized recipients that received subcutaneous estrogen pellet implants (Figure 6B). In contrast, SSM1 did not require ovarian hormones for in vivo growth (Figure 6B), revealing that not all STAT1 ${ }^{-1-}$ mammary tumor cells display hormone dependency. This result corresponds with the finding that most, but not all, tumor cells in the primary STAT1 ${ }^{-1-}$ mammary carcinomas display ER $\alpha$ and PR positivity (Figure 4). However, these hormone-independent cells are extremely rare in the primary $\mathrm{STAT}^{-/-}$mammary tumors as demonstrated by the fact that tumor fragments from two independent primary tumors failed to engraft in ovariectomized mice (Figure $6 \mathrm{C}$ ). Together, these results demonstrate that SSM2 and SSM3 are ovarian hormone-responsive and-dependent in vitro and in vivo and that SSM1 arises from a very rare subset of ER $\alpha^{-}$ cells and is used in this study as a hormone-nonresponsive cell line.

Having demonstrated that the STAT1 ${ }^{-1-} \mathrm{ER} \alpha^{+}$mammary tumor cells required ovarian hormones for establishment of tumor growth, we next examined whether these tumors also depended on ovarian hormones to maintain tumor progression. We used ovariectomy as the treatment modality since ovarian ablation is commonly used to treat premenopausal patients with $\mathrm{ER} \alpha^{+} / \mathrm{PR}^{+}$breast cancers [52]. Established SSM3 tumors continued to grow in sham-treated mice (Figure 6D). However, established tumors failed to progress after ovariectomy, 


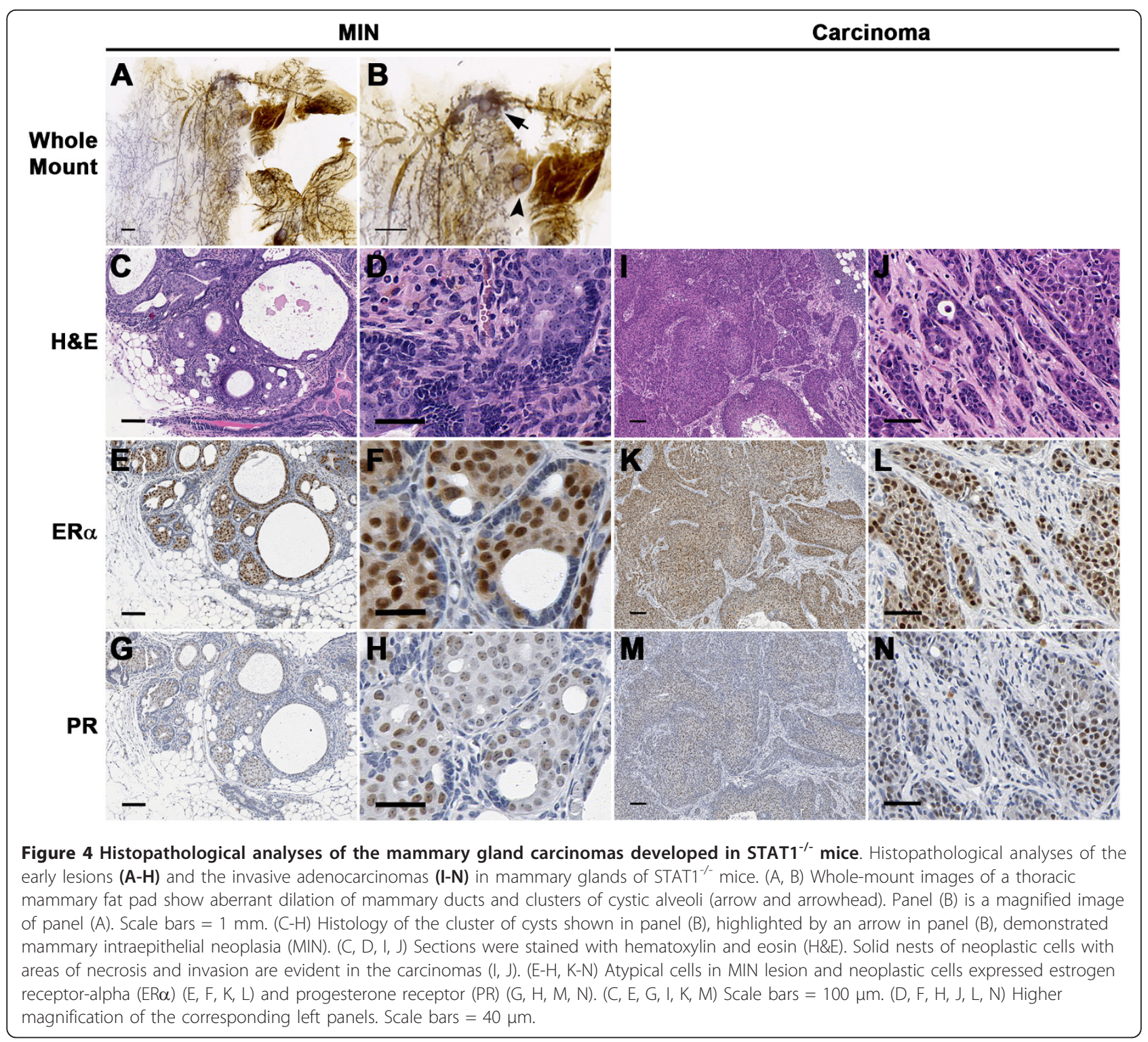

indicating that the $\mathrm{STAT} 1^{-/-} \mathrm{ER} \alpha^{+} / \mathrm{PR}^{+}$tumor cells require ovarian hormones not only for in vivo engraftment but also for maintenance of growth. Tumors that were established from transplanted primary tumor fragments were also highly sensitive to ovarian hormone deprivation and became unpalpable upon ovariectomy (Figure 6E). Thus, the STAT1 ${ }^{-1-}$ mammary tumors are functionally similar to human $\mathrm{ER}^{+} / \mathrm{PR}^{+}$breast cancers.

\section{$\mathrm{STAT}^{-/-}$mammary tumors display a surface marker phenotype reflective of luminal mammary tumors}

Hormone receptor expression is one of the critical parameters used to determine the suitable treatments for human patients with breast cancer [2]. In addition to hormone receptors, mammary tumors can be classified by biomarkers that are expressed on the tumor cell surface. Myoepithelial and luminal epithelial cells can be identified on the basis of the well-established differential expression of murine mammary epithelial cell population markers, CD49f and CD24 (that is, myoepithelial cells $=C D 49 f^{\text {hi }}$ CD $24^{\text {int }}$ and luminal epithelial cells $=$ CD49f ${ }^{\text {int }}$ CD24 ${ }^{\text {hi }}$ ) [31-33]. These two epithelial cell populations could be readily differentiated in nontransformed mammary glands of STAT1 ${ }^{-/-}$ mice ('myo' and 'lum' in Figure 7B) by flow cytometry upon elimination of dead cells and lineage-positive cells (Figure 7A). Marked expansion of the luminal epithelial cell subset was evident in MIN, the earliest stage of neoplastic changes identifiable by histology, in comparison with nontransformed mammary glands (Figure 7B). Further expansion of these luminal epithelial cells continued as MIN progressed to carcinomas 
A

\section{NMuMG}

SSM1

SSM2

SSM3

MCF7

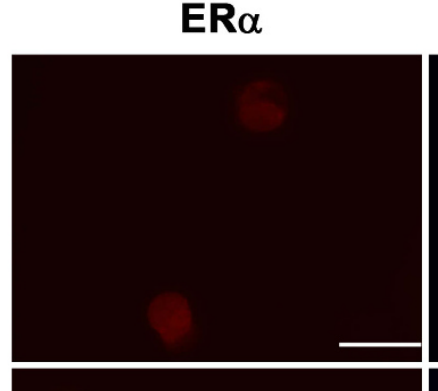

\section{$E R \alpha$}

DAPI
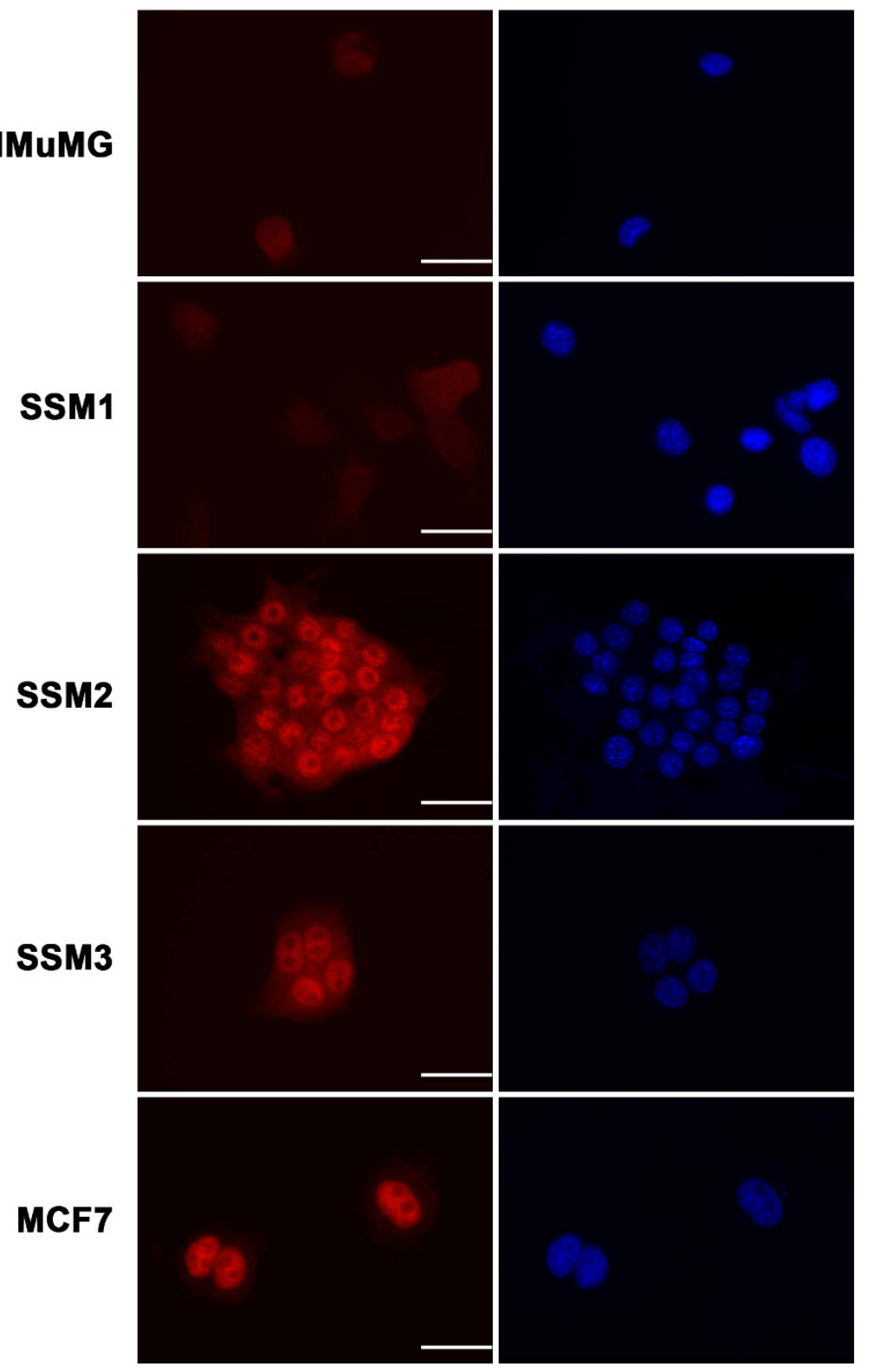

B

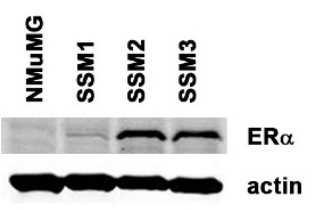

Figure $5 \mathrm{STAT}^{-/-}$mammary tumor cell lines SSM2 and SSM3 express estrogen receptor-alpha (ER $\alpha$ ), PR-A, and PR-B. (A) SSM2 and SSM3 expressed nuclear ER $\alpha$, similar to the human ER $\alpha^{+}$breast cancer cell line MCF7. In contrast, NMUMG and SSM1 did not exhibit nuclear $E R \alpha$ staining. Scale bars $=40 \mu \mathrm{m}$. (B) SSM2 and SSM3 are positive for ER $\alpha$ expression, but SSM1 expressed a very low level of ER $\alpha$, by Western blot analysis. NMUMG exhibited no detectable levels of ER $\alpha$. (C) SSM2 and SSM3 expressed PR-A and PR-B, which are derived from alternative PR promoters and are target genes for ER $\alpha$ signaling, suggesting that SSM2 and SSM3 were estrogen-responsive. In contrast, NMuMG and SSM1 did not display functional ERo signaling. DAPI, 4'-6-diamidino-2-phenylindole; SSM, spontaneous STAT1 ${ }^{-1}$ mammary (epithelial tumor cell line). 


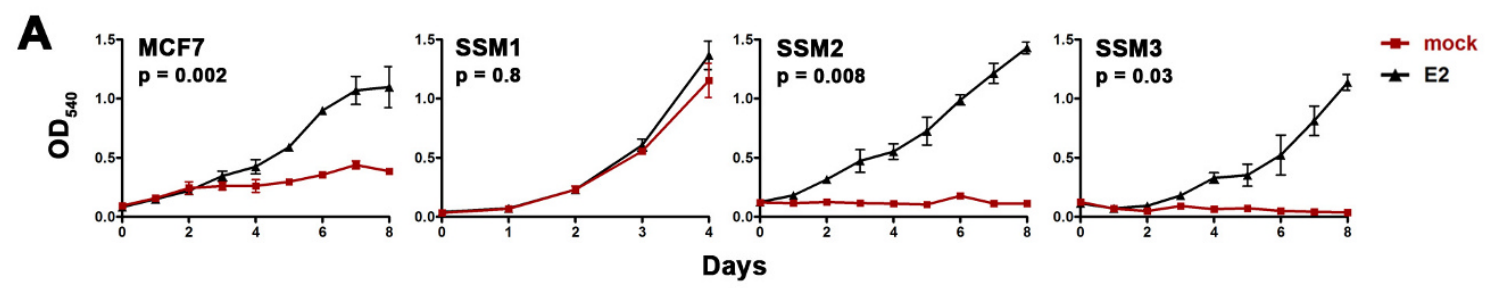

B
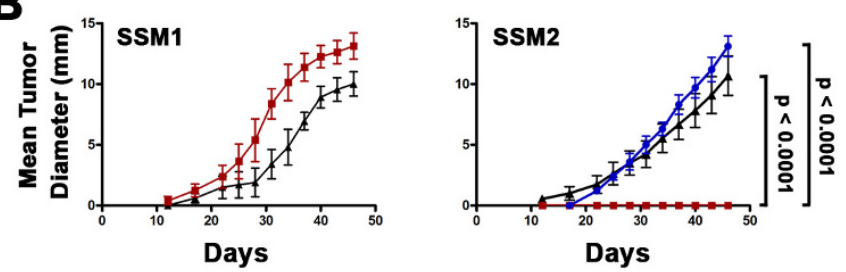

Days

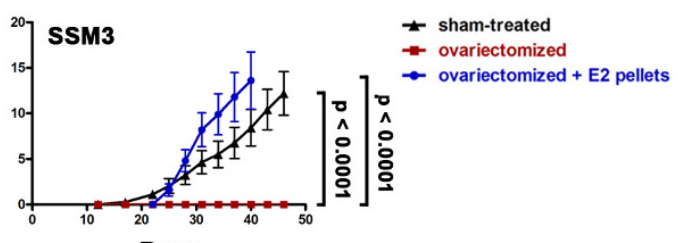

C

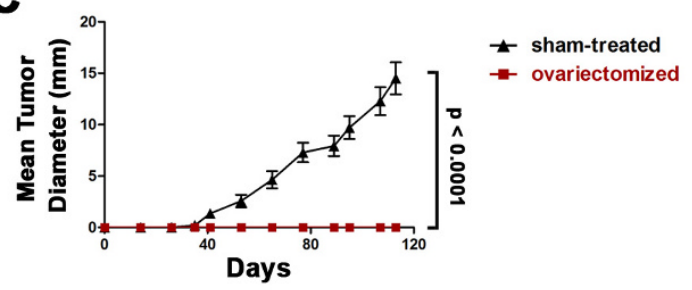

E

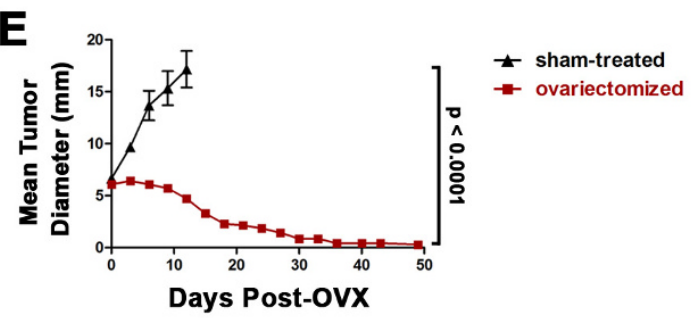

D

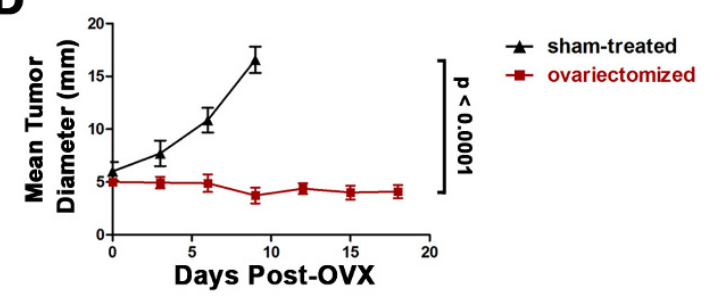

Figure $6 \mathrm{STAT}^{-/-}$mammary tumors respond to and depend on ovarian hormones for engraftment and tumor progression. (A) SSM1, SSM2, SSM3, or MCF7 was plated in phenol red-free media containing charcoal-treated fetal calf serum in the presence (17 $\beta$-estradiol, or E2; black triangles) or absence (mock; red squares) of $10 \mathrm{nM}$ E2. P values were obtained with $t$ test comparing mock-treated and E2-treated samples. (B) SSM1, SSM2, or SSM3 ( $10^{5}$ cells per mouse) was transplanted into the inguinal mammary glands of sham-treated (black triangles), ovariectomized (red squares), or ovariectomized wild-type or STAT1 ${ }^{--}$mice that were supplemented with E2 pellets (blue circles). $P$ values were obtained with $t$ test comparing tumor growth in ovariectomized mice with that in either sham-treated or ovariectomized mice supplemented with E2 pellets [44]. (C) Growth of tumor transplants from primary STAT1 ${ }^{-1-}$ mammary tumors is ovarian hormone-dependent. Fragments $(1 \times 1$ $\mathrm{mm}^{2}$ ) from two primary STAT1 ${ }^{-1}$ mammary tumors were transplanted into the inguinal fat pads of ovariectomized mice (red) or sham-operated mice (black). No palpable masses were detected in ovariectomized mice. In contrast, tumors grew progressively in recipients with intact ovaries. Results represent seven to eight mice in each group $(P<0.0001)$. (D) SSM3 tumor cells were transplanted orthotopically into the mammary fat pads of nude mice. Mice bearing established tumors around $5 \mathrm{~mm}$ in diameter were sham-operated (black triangles; $n=7$ ) or ovariectomized (red squares; $n=9$ ). SSM3 tumors failed to progress in the absence of ovarian hormones, demonstrating sensitivity to ovarian hormone deprivation therapy $(P<0.0001)$. (E) Fragments of primary STAT1 ${ }^{-1}$ mammary tumors were transplanted into the mammary fat pads of STAT1 ${ }^{-1}$ mice. When the established tumors reached $5 \mathrm{~mm}$ in diameter, the animals were either sham-operated (black triangles; $n=3$ ) or ovariectomized (red squares; $n=7$ ). Transplanted primary tumors regressed after ovarian hormone deprivation $(P<0.0001)$. Error bars indicate standard error of the mean. $\mathrm{OD}_{540}$, optical density at $540 \mathrm{~nm}$; OVX, ovariectomy; SSM, spontaneous STAT1 ${ }^{-1}$ mammary (epithelial tumor cell line).

(Figure 7B). Neoplastic cells in carcinomas homogeneously displayed a CD49f ${ }^{\text {int }} \mathrm{CD} 24^{\text {hi }}$ phenotype. Consistent with this result, primary STAT1 $1^{-1-}$ mammary tumors are strongly positive for the luminal epithelial markers, CK19 and CK8/18 (Figure 7C). Occasional
$\mathrm{CK} 5^{+}, \mathrm{CK} 14^{+}$, or $\mathrm{p} 63^{+}$myoepithelial cells were observed (Figure 7C and data not shown). Together, these results indicate that the STAT1 ${ }^{-1-}$ mammary tumor cells exhibit a marker phenotype that is characteristic of luminal epithelial cells. 


\section{A}
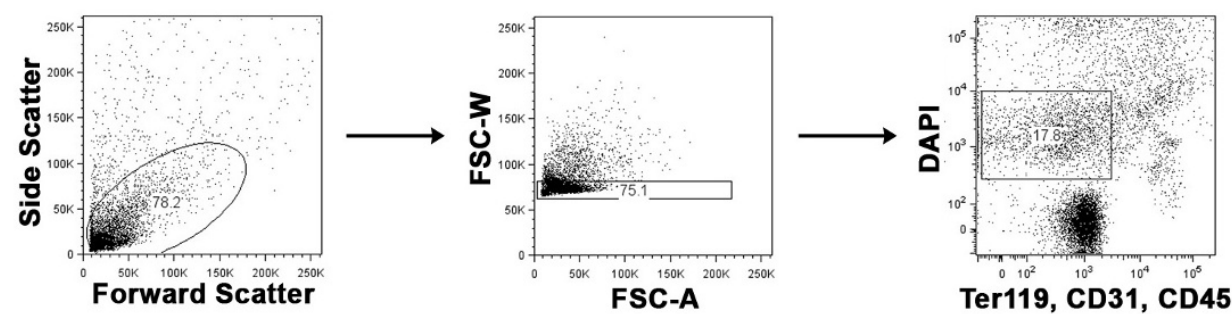

B
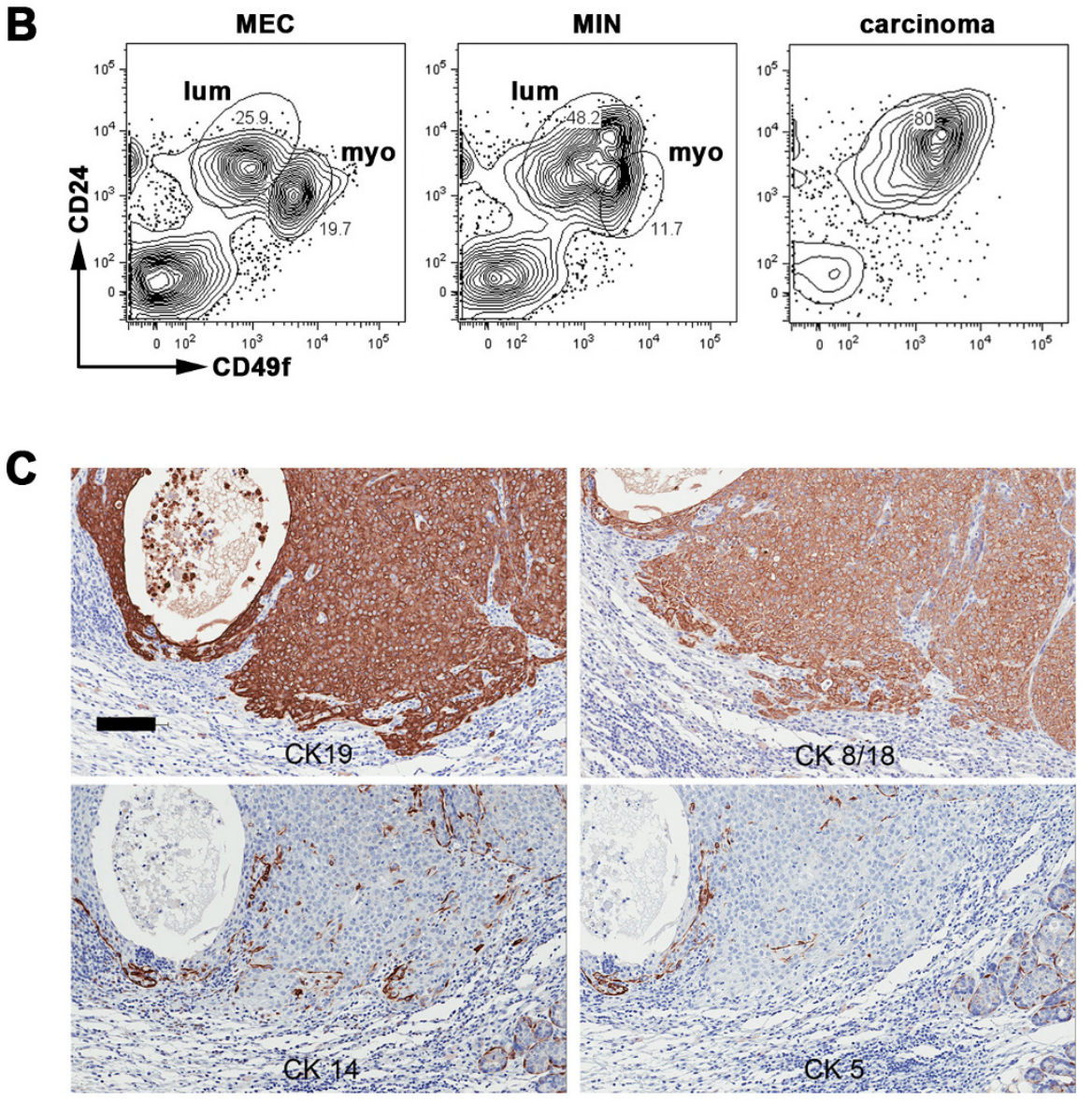

Figure $7 \mathrm{STAT}^{-/-}$mammary tumor cells display a luminal epithelial cell phenotype. (A) Gating procedure used for the analysis of cell surface markers. Disaggregated mammary glands or mammary tumors were collected by an LSRIl flow cytometer and analyzed by using FlowJo. Cells were first selected on the basis of size by using forward and side scatter (left panel). Single cells were then selected by forward scatter (FSC)-A and FSC-W (middle panel). Live cells (DAPI') and lineage cells (Ter119-, CD31', and CD45) were gated for the analysis depicted in (B). (B) Expression of CD49f and CD24 on STAT1 ${ }^{-1}$ mammary epithelial cells (MECs), mammary intraepithelial neoplasia (MIN), and carcinoma.

Representative images from five STAT1 ${ }^{-1}$ mice are shown. Myoepithelial (myo) and luminal epithelial (lum) are highlighted. (C)

Immunohistochemical analysis of primary STAT1 ${ }^{-1}$ mammary tumors for cytokeratin (CK) 5, 14, 8/18, and 19. Mammary tumor cells were stained positive for CK19 and CK8/18 (luminal epithelial markers) but negative for CK5 and CK14 (myoepithelial markers). Scale bar = 100 um. DAPI, 4'-6diamidino-2-phenylindole. 
$\mathrm{STAT1}^{-/-}$mammary tumors exhibit human luminal breast cancer-like molecular signatures

Perou and colleagues $[3,53]$ reported previously that human breast cancers could be differentiated into five molecular subtypes (luminal A, luminal B, HER2, basal, and normal-like) on the basis of their gene expression profiles. Strikingly, when gene expression patterns of mammary tumors from 13 different pre-existing mouse breast cancer models were compared with those of 232 human breast cancers, none showed significant overlap with human $E R \alpha^{+}$luminal breast cancers [36]. To extend these findings, we compared the gene expression patterns of the aforementioned datasets (primary data generously provided by Dr. Charles M Perou, University of North Carolina at Chapel Hill) with those of five primary $\mathrm{STAT}^{-/-} \mathrm{ER}^{+}$mammary tumors. Hierarchical clustering analysis revealed that the five primary
$\mathrm{STAT}^{-1-} \mathrm{ER}^{+}$mammary tumors not only resembled one another but also closely resembled human luminal breast cancers (Figure 8A). STAT1 ${ }^{-/-} \mathrm{ER}^{+}$mammary tumors also showed elevated transcription of genes characteristic of luminal breast cancers (for example, keratin 8, keratin 18, XBP1, GATA3, MYB, AREG, and $F O X A 1)$ (Figure $8 \mathrm{~B}$ ). In agreement with the previous report [36], samples from other mouse mammary tumor models consistently clustered away from human luminal breast cancers (Figure 8A). Finally, analyses using two other statistical methods (sigClust [42] and consensus clustering [43]) also supported the conclusion that $\mathrm{STAT}^{-1-} \mathrm{ER}^{+}$mammary tumors grouped more consistently and reproducibly with human luminal breast cancers than any other mouse mammary tumor model (see Materials and methods). Specifically, results from the consensus clustering analysis indicated that the

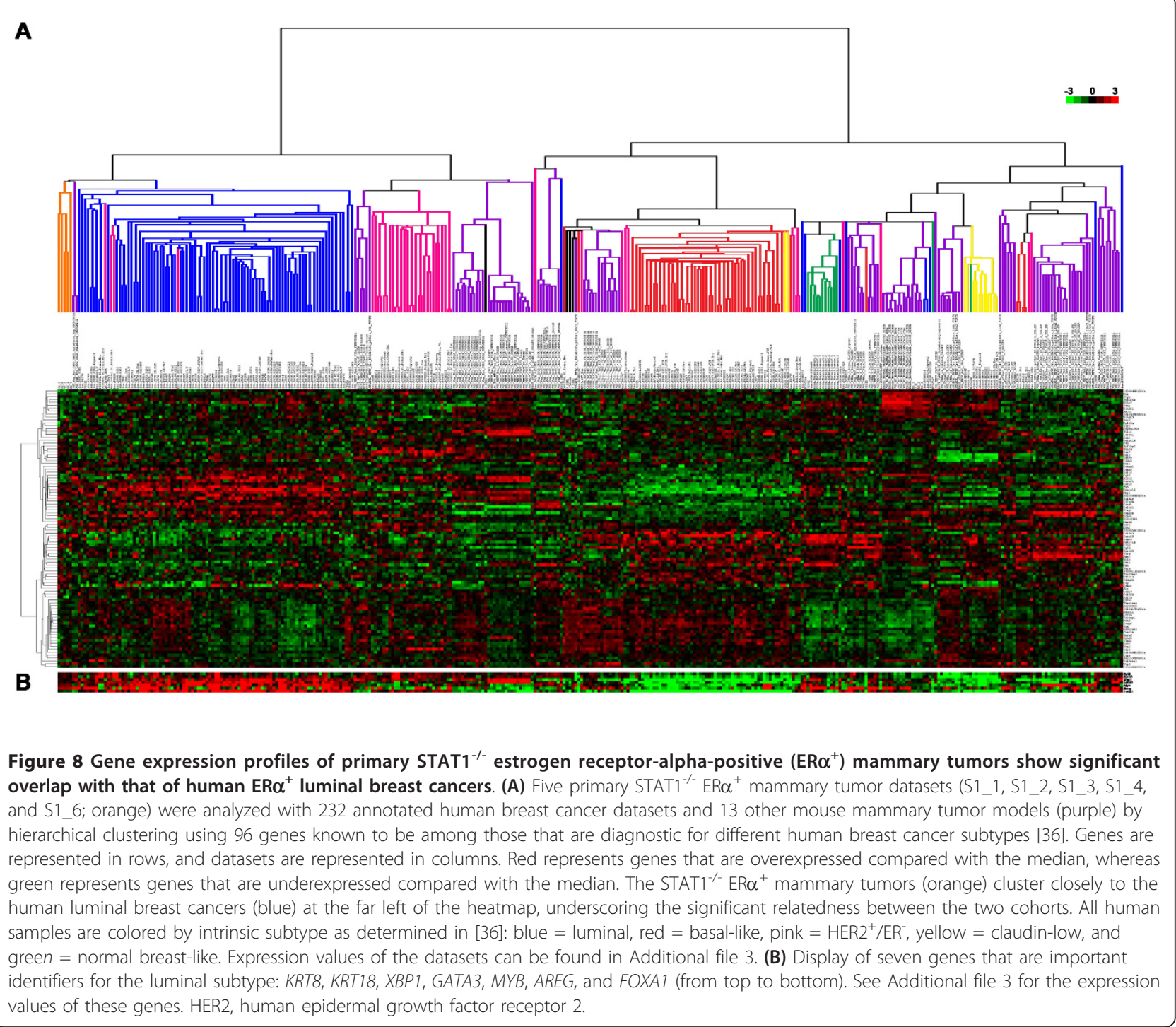


$\mathrm{STAT}^{-1-}$ mammary tumors and human luminal breast cancers clustered $62 \%$ of the time upon 1,000 re-samplings but that the MMTV-Neu and MMTV-PyMT clustered with human luminal breast cancers only $42 \%$ of the time upon 1,000 re-samplings. Together, the $\mathrm{STAT1}^{-1-} \mathrm{ER}^{+}$mammary tumors display high molecular homogeneity and a striking similarity to human luminal breast cancers.

\section{A cell-autonomous role of STAT1 in suppressing mammary tumor formation}

The above observations led us to conclude that STAT1 suppresses tumor development in the mammary gland. It is possible that STAT1 confers this role by mediating the elimination phase of immunoediting. However, since the immunodeficient $\mathrm{RAG}^{-/-}$mice never developed mammary tumors and the loss of STAT1 expression was observed only in the neoplastic cells of human breast cancers, we hypothesized that STAT1 might act as a cell-intrinsic tumor suppressor in mammary epithelium. We first investigated whether enforced expression of STAT1 in STAT1 ${ }^{-1-}$ mammary tumor cells affected their tumorigenic phenotype. This approach has been used in the past to define several other tumor suppressors [54]. Retroviral transduction of WT STAT1 into
SSM1, SSM2, and SSM3 resulted in expression of STAT1 protein levels in each cell line comparable to that in unmanipulated NMuMG (Figure 9A). Enforced expression of WT STAT1 led to apoptosis of a substantial percentage of SSM2 and SSM3 but not of SSM1 or NMuMG (Figure 9B). Therefore, the tumor suppression function of STAT1 is cell-autonomous.

Since phosphorylation at the tyrosine residue at position 701 synergizes with that at the serine residue at position 727 of STAT1 to effect the maximal transcriptional activity $[53,55]$, two STAT1 mutants, one lacking the Tyr residue (Y701F) and one lacking the Ser residue (S727A), were tested for their ability to induce tumor cell death. Even when expressed at levels comparable to those achieved with WT STAT1, the Y701F mutant was unable to induce apoptosis when expressed in SSM2 and SSM3 (Figure 9C). In contrast, the S727A mutant displayed an indistinguishable phenotype as the WT STAT1. Thus, the tumor suppressor action of STAT1 requires tyrosine phosphorylation, but not serine phosphorylation, of STAT1.

\section{Discussion}

Current dogma, based on gene expression analyses of intact breast cancer biopsies, holds that STAT1 mRNA

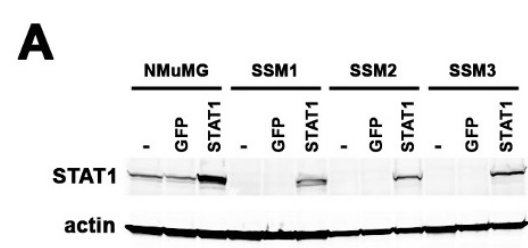

B

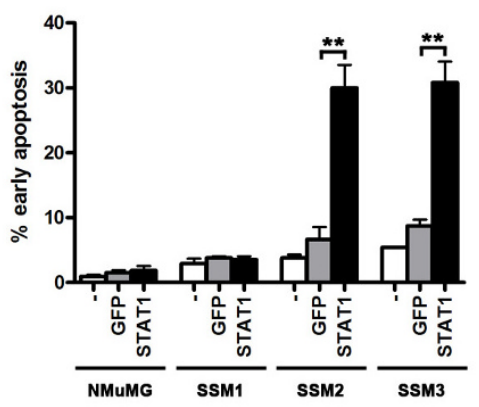

C

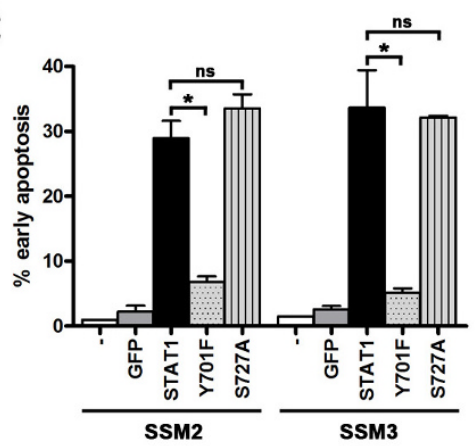

Figure 9 Tumor suppressor function of STAT1 is cell-autonomous. (A) STAT1 was ectopically expressed in SSM1, SSM2, and SSM3 by retroviral transduction (STAT1) to levels comparable to the endogenous level in nontransduced (-) NMuMG. STAT1 was also overexpressed in NMUMG (STAT1). Retrovirus expressing GFP alone was used as a negative control (GFP). (B) STAT1 reconstitution in SSM2 and SSM3 resulted in 4.5- and 3.5-fold increases in early apoptosis (that is, annexin V-positive, 7-AAD-negative cells) 3 days post-transduction, respectively. ${ }^{* *} P<0.005$. (C) Tyrosine 701 is required for STAT1-mediated apoptosis in SSM2 and SSM3. Retrovirus expressing GFP, WT STAT1 (STAT1), and STAT1 mutants (Y701F or S727A) were transduced into SSM2 and SSM3. Mutation in Y701 (Y701F) abolished the ability of STAT1 to induce cell death, whereas that in S727 (S727A) was still capable of inducing cell death. SSM2, ${ }^{*} P=0.02$. SSM3, ${ }^{*} P=0.04$. $P$ values were obtained with unpaired $t$ test. ns, not significant; SSM, spontaneous STAT1 ${ }^{-/-}$mammary (epithelial tumor cell line). 
levels are elevated in breast cancer tissues compared with normal breast tissues [3], leading to the hypothesis that STAT1 might facilitate tumor outgrowth. Here, we have presented a novel finding demonstrating a selective loss of STAT1 expression in neoplastic epithelial cells, but not in the surrounding stromal cells, compared with normal mammary epithelium. Additionally, this tumor cell-specific effect was observed more frequently in ER $\alpha$ ${ }^{+}$than in ER $\alpha^{-}$human breast cancers. Therefore, an increase in STAT1 mRNA levels in the subset of breast cancer cases that exhibit low STAT1 expression in the neoplastic cells could be explained by a selective upregulation of STAT1 transcription in the stromal cells alone. Our findings thus indicate that the regulation of STAT1 expression is cell context-dependent and a STAT1 activation signature in whole-tumor biopsy might not reflect the biology of the entire tumor microenvironment. The clinical implication of these findings is that caution should be taken in interpreting the involvement of STAT1 in treatment outcomes when STAT1 activation signature in whole-tumor biopsies is used as a prognostic indicator.

Since downregulation of STAT1 expression is restricted to the neoplastic epithelial cells but not to the surrounding stromal cells, somatic silencing of STAT1 transcription may occur preferentially in the breast cancer cells. STAT1 promoter methylation in squamous cell carcinomas and prostate cancers has been proposed to be a mechanism whereby STAT1 transcription is repressed during transformation [56,57]. It is conceivable that STAT1 promoter methylation is likewise in action during breast cancer progression. However, we cannot eliminate the possibility that STAT1 downregulation occurs at the post-transcriptional level. Investigation undertaken to differentiate these possibilities and to determine whether STAT1 loss correlates with clinical outcome is ongoing.

To investigate the role of STAT1 in mammary tumorigenesis, we employed a novel murine system that provided mechanistic insights into the physiological consequence of loss of STAT1 expression. Specifically, we find, much to our surprise, that STAT1 ${ }^{-1-}$ female mice spontaneously develop mammary gland adenocarcinomas that show remarkable similarities to human $E R \alpha^{+}$luminal breast cancers. Pathologically, the $\mathrm{STAT}^{-1-}$ mammary tumors progress from a preneoplastic state classified as mammary intraepithelial neoplasia to adenocarcinoma, mirroring the progression of human breast cancer from atypical hyperplasia to ductal carcinoma in situ and finally to invasive carcinoma. The hormone receptor status of the STAT1 $1^{-1-}$ mammary tumors also shows a remarkable parallel to human $E R \alpha^{+} / \mathrm{PR}^{+}$ breast cancers. Biologically, STAT1 ${ }^{-1-}$ mammary tumor cells depend on ovarian hormones for both the initiation and the maintenance of tumor growth. CD $49 \mathrm{f}^{\mathrm{int}} \mathrm{CD} 24^{\text {hi }}$ luminal epithelial cells are enriched for hormone receptor-positive cells that are rarely found in the myoepithelial cell subset [58]. It is tempting to speculate that the tumor-initiating cells in the STAT1 ${ }^{-1-}$ mammary tumors reside in the luminal epithelial subset because of the significant expansion of these cells in the preneoplastic lesions. Future work will be focused on elucidating the nature of these tumor-initiating cells.

The penetrance of multiparous STAT1 ${ }^{-1-}$ mice is remarkably close to $100 \%$, suggesting that pregnancyassociated hormones can accelerate tumorigenesis. At present, it is not possible to conclude that these hormones are required for the tumorigenesis of the $\mathrm{STAT}^{1 /-}$ mammary glands since nulliparous STAT1 ${ }^{-1-}$ mice also develop mammary tumors. While elucidating the roles of pregnancy-associated hormones in mammary tumorigenesis will be the target for future investigation, work investigating the mechanism by which STAT1 suppresses tumor formation has begun. We employed a classic approach that has been used to validate tumor suppressors in the past [54]. Similar to the classic tumor suppressors, restoration of WT STAT1 in the $\mathrm{STAT}^{-1-}$ mammary tumor cells spontaneously causes tumor cell death. Our findings thus demonstrate that the tumor suppressor function of STAT1 is cellautonomous. A mutant form of STAT1 lacking the functionally critical Tyr 701 residue is defective in this function, suggesting that STAT1 suppresses tumor formation by regulating the transcription of its target genes. Since phosphorylation in Ser 727 is functionally distinct from and independent of that in Tyr 701 $[55,59,60]$, the inability of the S727A mutant to abrogate cell death suggests that tumor suppression mediated by STAT1 does not require S727-dependent target genes, like GBP-1 [55]. Although we cannot completely eliminate the possibility that STAT1 can also act as an extrinsic tumor suppressor via its ability to mediate functional anti-tumor immunity, the cell-intrinsic effect of STAT1 is consistent with recent studies demonstrating a role for STAT1 in suppressing ErbB2/Neu-driven tumor formation [21,22]. Epithelial-specific deletion of STAT1 accelerates tumor development in the ErbB2/ Neu tumor model. Therefore, STAT1 might exert a broader tumor suppression function against multiple oncogenic pathways. It is then noteworthy that STAT1 expression is also diminished in the neoplastic cells of $22 \%$ of the human HER2 ${ }^{+}$breast cancer cases that we examined in this study.

Although the current repertoire of endocrine therapy is remarkably effective in treating $\mathrm{ER} \alpha^{+}$breast cancers, about $30 \%$ to $50 \%$ of the patients still suffer from recurrences [61-63]. Novel therapeutic targets for the treatment of $\mathrm{ER}^{+}$breast cancers are, therefore, still needed. 
Preclinical models of human $\mathrm{ER} \alpha^{+} / \mathrm{PR}^{+}$breast cancers are essential for the testing of new treatments. However, only a limited number of models produce tumors that contain a significant proportion of hormone-dependent $\mathrm{ER}^{+} / \mathrm{PR}^{+}$tumor cells [5-8]. In addition, very little is known about the molecular characteristics of the few existing mouse $\mathrm{ER} \alpha^{+} / \mathrm{PR}^{+}$tumor cell lines and thus it has not been possible to establish their genetic relationship to human luminal breast cancers. In contrast, $\mathrm{STAT}^{-1-}$ mammary tumors exhibit well-defined tumor progression kinetics and a set of highly reproducible and homogeneous histopathological, biological, and molecular characteristics that closely resemble human luminal breast cancers. Most importantly, STAT1 ${ }^{-1-}$ mammary tumors express elevated levels of ER $\alpha$, PR, GATA3, AREG, XBP1, and FOXA1, all of which are regulated by the transcriptional control of ER $\alpha$. In agreement with this activated ER $\alpha$ genetic signature, $\mathrm{STAT}^{-1-}$ mammary tumor is also a unique preclinical model because of its sensitivity to standard endocrine therapy, including estrogen deprivation therapy (this study) and treatment targeting ER $\alpha$ (AM Fowler and MJ Welch, manuscript in preparation). Furthermore, STAT1 ${ }^{-1-}$ mammary tumor cells are transplantable orthotopically into both immunocompetent and immunodeficient mice, facilitating the examination of immune-based therapies, which otherwise would not be possible in xenograft models using $\mathrm{ER} \alpha^{+} / \mathrm{PR}^{+}$human breast cancer cell lines. Thus, this model not only allows one to study the entire developmental program of luminal mammary tumorigenesis but also permits short-term experiments using a tumor cell transplantation approach. For these reasons, the $\mathrm{STAT}^{-1-}$ mammary tumor is an exceptional model for human $\mathrm{ER}^{+} \mathrm{PR}^{+}$luminal breast cancers.

\section{Conclusions}

The important findings of this study are that loss of STAT1 expression is a frequent event during the progression of human breast cancers and that loss of functional STAT1 in mice causes spontaneous development of mammary adenocarcinomas. These murine STAT $1^{-1-}$ mammary tumors closely recapitulate the progression and biology of human $\mathrm{ER}^{+}$luminal breast cancers. This is underscored by the potent anti-tumor action of ovarian ablation therapy on the STAT $1^{-1-}$ mammary tumors. Our results thus validate the physiological relevance of our novel mouse $\mathrm{ER}^{+} / \mathrm{PR}^{+} \mathrm{STAT}^{-1-}$ mammary tumors for potential translatability to human breast cancer research.

\section{Additional material}

Additional file 1: Supplementary Figure 1. Evidence against translocation of endogenous murine mammary tumor virus (MMTV) as the cause of $\mathrm{STAT}^{-/-}$mammary tumorigenesis. Southern blot analysis was used to detect the translocation of MMTV long terminal repeats (LTR). Genomic DNA was harvested from nontransformed mammary glands of young or aged nulliparous STAT $1^{-1-}$ mice (lanes 2, 3, 12, and 13), nontransformed mammary glands of retired STAT1 ${ }^{-1-}$ breeders (lanes 4 and 14), primary STAT1 ${ }^{-1-}$ mammary tumors (lanes 6, 7, 16 , and 17), or SSM cell lines established from primary STAT1 ${ }^{-1}$ mammary tumors (lanes 8 to 10 and lanes 18 to 20) and digested with either EcoRI (lanes 1 to 10) or Pvull (lanes 11 to 20). The number and the sizes of the DNA fragments hybridized to the MMTV LTR in these samples are indistinguishable from those in WT mammary glands (lanes 1 and 11) and STAT1 ${ }^{-1}$ splenocytes (lanes 5 and 15), arguing against an association between MMTV LTR translocation and mammary tumorigenesis in $\mathrm{STAT}^{-1-}$ mammary glands.

Additional file 2: Supplementary Figure 2. Establishment of Spontaneous STAT1 ${ }^{-/-}$Mammary (SSM) epithelial tumor cell lines. (A) Primary STAT1 ${ }^{-1}$ mammary tumors were mechanically dissociated and then digested in collagenese solution. Disaggregated tumor and stromal cells were analyzed for the expression of cytokeratin as a marker for epithelial cells (green) and vimentin as a marker for mesenchymal cells (red) by immunofluoresence. Freshly disaggregated tumors were comprised of epithelial tumor cells (green) and stromal fibroblasts (red). (B, C, and D) Epithelial tumor cell lines SSM1 (B), SSM2 (C), and SSM3 (D) are devoid of stromal fibroblasts as evidenced by the complete absence of vimentin-positive cells. Representative images from 8 independent experiments.

Additional file 3: This file contains the expression values of 96 genes that were used in Figure 8 to classify 232 human breast cancer datasets, 13 mouse mammary models datasets and primary $\mathrm{STAT}^{-/-}$mammary tumors.

\section{Abbreviations}

CK: cytokeratin; DAPI: 4'-6-diamidino-2-phenylindole; DMEM/F12: Dulbecco's modified Eagle's medium/F12; E2: estradiol; ERa: estrogen receptor-alpha; FBS: fetal bovine serum; H\&E: hematoxylin and eosin; HER2: human epidermal growth factor receptor 2; IFN: interferon; IQR: interquartile range; MIN: mammary intraepithelial neoplasia; PBS: phosphate-buffered saline; PR: progesterone receptor; S1N: STAT1-null; Ser: serine; SSM: spontaneous $\mathrm{STAT}^{-1-}$ mammary (epithelial tumor cell line); Tyr: tyrosine; WT: wild-type.

\section{Acknowledgements}

The authors thank Drs. Paul Allen, Barry Sleckman, Emil Unanue, Ravi Uppaluri, Matthew Vesely (Washington University School of Medicine), Mark Smyth (Peter McCallum Cancer Centre), and Michel Aguet (Swiss Institute for Experimental Cancer Research) for critical review of the manuscript. The authors are grateful to Dr. Charles M Perou (University of North Carolina at Chapel Hill) for providing datasets for human breast cancers and mouse mammary tumors, Drs. David Wang and Kathie Mihindukulasuriya (Washington University School of Medicine) for performing viral microarray analyses, and Jessica Archambault and James Michael White (Washington University School of Medicine), Katie Bell (University of California, Davis), and Wei Zhu (New York University School of Medicine) for their excellent technical assistance. This work was supported by a Susan G Komen Foundation Postdoctoral Fellowship Award (SRC), a Finnel Family Fund Grant from the Cancer Research Institute (RDS), and grants from the National Cancer Institute (MJW, RDC, and RDS), National Institute of Allergy and Infectious Diseases (DEL), the Ludwig Institute for Cancer Research (RDS), and Fondazione Beretta (Brescia, Italy) (WV).

\section{Author details}

${ }^{1}$ Department of Pathology and Immunology, Washington University School of Medicine, 425 S. Euclid Avenue, St. Louis, MO 63110, USA. ²Department of Pathology, University of Brescia/Spedali Civilli di Brescia, Piazzale Spedali Civili 1, Brescia 25123, Italy. ${ }^{3}$ Division of Biostatistics, Washington University School of Medicine, 660 S. Euclid Avenue, St. Louis, MO 63110, USA. ${ }^{4}$ Division of Radiological Sciences, Edward Mallinckrodt Institute of Radiology, 660 S. Euclid Avenue, St. Louis, MO 63110, USA. ${ }^{5}$ Center for Comparative Medicine, Department of Pathology and Laboratory Medicine, University of California 
Davis, County Road 98 and Hutchison Drive, Davis, CA 95616, USA. ${ }^{6}$ Department of Pathology, New York University School of Medicine, 550 First Avenue, MSB 548, New York, NY 10016, USA.

\section{Authors' contributions}

SRC conceived and planned the study, analyzed data, wrote the paper, analyzed the results, monitored mammary tumor development in different cohorts of mice, generated the SSM cell lines, and performed all of the biochemical, molecular, and in vivo studies. RDS conceived and planned the study, analyzed data, and wrote the paper. SL performed immunohistochemical studies on the human breast cancer biopsies. WV and $\mathrm{LL}$ analyzed the results. DEL monitored mammary tumor development in different cohorts of mice. JL performed gene expression profiling analyses and oversaw all statistical analyses. LJTY performed whole-mount analyses. CR performed Southern blotting. CA performed molecular studies. AMF and MJW contributed to study design. RDC analyzed the pathology of the $\mathrm{STAT}^{-1-}$ mammary tumors. All authors read and approved the final manuscript.

\section{Competing interests}

The authors declare that they have no competing interests.

Received: 8 September 2011 Revised: 19 October 2011

Accepted: 20 January 2012 Published: 20 January 2012

\section{References}

1. Anderson WF, Chatterjee N, Ershler WB, Brawley OW: Estrogen receptor breast cancer phenotypes in the surveillance, epidemiology, and end results database. Breast Cancer Res Treat 2002, 76:27-36.

2. Bundred NJ: Prognostic and predictive factors in breast cancer. Cancer Treat Rev 2001, 27:137-142

3. Perou CM, Sorlie T, Eisen MB, van de Rijn M, Jeffrey SS, Rees CA, Pollack JR, Ross DT, Johnsen $\mathrm{H}$, Akslen LA, Fluge O, Pergamenschikov A, Williams C, Zhu SX, Lonning PE, Borresen-Dale AL, Brown PO, Botstein D: Molecular portraits of human breast tumours. Nature 2000, 406:747-752.

4. Chia $Y H$, Ellis MJ, Ma CX: Neoadjuvant endocrine therapy in primary breast cancer: indications and use as a research tool. Br J Cancer 2010, 103:759-764

5. Simian M, Manzur T, Rodriguez $V$, de Kier Joffe EB, Klein S: A spontaneous estrogen dependent, tamoxifen sensitive mouse mammary tumor: a new model system to study hormone-responsiveness in immune competent mice. Breast Cancer Res Treat 2009, 113:1-8.

6. Kumar MJM, Ponvijay KS, Nandhini R, Nagarajan RS, Jose J, Srinivas G, Nagarajan P, Venkatesan R, Kumar K, Singh S: A mouse model for lumina epithelial like ER positive subtype of human breast cancer. BMC Cancer 2007, 7:180.

7. Efeyan A, Fabris V, Merani S, Lanari C, Molinolo AA: Establishment of two hormone-responsive mouse mammary carcinoma cell lines derived from a metastatic mammary tumor. Breast Cancer Res Treat 2004, 83:233-244.

8. Aidells $\mathrm{BD}$, Daniel $\mathrm{CW}$ : Hormone-dependent mammary tumors in strain GR/A mice. III. Effectiveness of supplementary hormone treatments in inducing tumorous phase growth. J Natl Cancer Inst 1976, 57:527-537.

9. Bach EA, Aguet M, Schreiber RD: The IFNy receptor: a paradigm for cytokine receptor signaling. Annu Rev Immunol 1997, 15:563-591.

10. Meraz MA, White JM, Sheehan KCF, Bach EA, Rodig SJ, Dighe AS, Kaplan DH, Riley JK, Greenlund AC, Campbell D, Carver-Moore K, DuBois RN, Clark R, Aguet M, Schreiber RD: Targeted disruption of the Stat1 gene in mice reveals unexpected physiologic specificity in the JAK-STAT signaling pathway. Cell 1996, 84:431-442.

11. Durbin JE, Hackenmiller R, Celeste Simon M, Levy DE: Targeted disruption of the mouse Stat1 gene results in compromised innate immunity to viral disease. Cell 1996, 84:443-450.

12. Kaplan DH, Shankaran V, Dighe AS, Stockert E, Aguet M, Old L, Schreiber RD: Demonstration of an interferon $\gamma$-dependent tumor surveillance system in immunocompetent mice. Proc Natl Acad Sci USA 1998, 95:7556-7561.

13. Shankaran V, Ikeda H, Bruce AT, White JM, Swanson PE, Old L, Schreiber RD: IFN $\gamma$ and lymphocytes prevent primary tumour development and shape tumour immunogenicity. Nature 2001 410:1107-1111.
14. Dunn GP, Koebel CM, Schreiber RD: Interferons, immunity and cancer immunoediting. Nat Rev Immunol 2006, 6:836-848.

15. Kumar A, Commane M, Flickinger TW, Horvath CM, Stark GR: Defective TNF-a-induced apoptosis in STAT1-null cells due to low constitutive levels of caspases. Science 1997, 278:1630-1632.

16. Wang S, Raven JF, Durbin JE, Koromilas AE: Stat1 phosphorylation determines Ras oncogenicity by regulating p $27^{\text {kip } 1}$. PLoS One 2008, 3 : e4376.

17. Lee C-K, Smith E, Gimeno R, Gertner R, Levy DE: STAT1 affects lymphocyte survival and proliferation partially independent of its role downstream of IFN-ү. J Immunol 2000, 164:1286-1292.

18. Ouchi F, Lee SW, Ouchi M, Aaronson SA, Horvath CM: Collaboration of signal transducer and activator of transcription 1 (STAT1) and BRCA1 in differential regulation of IFNy target genes. Proc Natl Acad Sci USA 2000, 97:5208-5213.

19. Townsend PA, Cragg MS, Davidson SM, McCormick J, Barry S, Lawrence KM, Knight RA, Hubank M, Chen P-L, Latchman DS, Stephanou A: STAT-1 facilitates the ATM activated checkpoint pathway following DNA damage. J Cell Sci 2005, 118:1629-1639.

20. Mullan PB, Hosey AM, Buckley NE, Quinn JE, Kennedy RD, Johnston PG, Harkin DP: The 2,5 oligoadenylate synthetase/RNaseL pathway is a novel effector of BRCA1- and interferon-gamma-mediated apoptosis. Oncogene 2005, 24:5492-5501.

21. Raven JF, Williams V, Wang S, Tremblay ML, Muller WJ, Durbin JE, Koromilas AE: Stat1 is a suppressor of ErbB2/Neu-mediated cellular transformation and mouse mammary gland tumor formation. Cell Cycle 2011, 10:794-804.

22. Klover PJ, Muller WJ, Robinson GW, Pfeiffer RM, Yamaji D, Hennighausen L: Loss of STAT1 from mouse mammary epithelium results in an increased Neu-induced tumor burden. Neoplasia 2010, 12:899-905.

23. Khodarev NN, Beckett M, Labay E, Darga T, Roizman B, Weichselbaum RR: STAT1 is overexpressed in tumors selected for radioresistance and confers protection from radiation in transduced sensitive cells. Proc Natl Acad Sci USA 2004, 101:1714-1719.

24. Khodarev NN, Minn AJ, Efimova EV, Darga TE, Labay E, Beckett M, Mauceri HJ, Roizman B, Weichselbaum RR: Signal transducer and activator of transcription 1 regulates both cytotoxic and prosurvival functions in tumor cells. Cancer Res 2007, 67:9214-9220.

25. Weichselbaum RR, Ishwaran H, Yoon T, Nuyten DS, Baker SW, Khodarev N, Su AW, Shaikh AY, Roach P, Kreike B, Roizman B, Bergh J, Pawitan Y, van de Vijver MJ, Minn AJ: An interferon-related gene signature for DNA damage resistance is a predictive marker for chemotherapy and radiation for breast cancer. Proc Natl Acad Sci USA 2008, 105:18490-18495.

26. Khodarev N, Ahmad R, Rajabi H, Pitroda S, Kufe T, McClary C, Joshi MD, MacDermed D, Weichselbaum R, Kufe D: Cooperativity of the MUC1 oncoprotein and STAT1 pathway in poor prognosis human breast cancer. Oncogene 2010, 29:920-929.

27. Harvey JM, Clark GM, Osborne CK, Allred DC: Estrogen receptor status by immunohistochemistry is superior to the ligand-binding assay for predicting response to adjuvant endocrine therapy in breast cancer. J Clin Oncol 1999, 17:1474-1481.

28. Shinkai Y, Rathbun G, Lam KP, Oltz EM, Stewart V, Mendelsohn M, Charron J, Datta M, Young F, Stall AM, Alt FW: RAG-2-deficient mice lack mature lymphocytes owing to inability to initiate $V(D) J$ rearrangement. Cell 1992, 68:855-867.

29. Ramsden DA, Gellert M: Formation and resolution of double-strand break intermediates in V(D)J rearrangement. Genes Dev 1995, 9:2409-2420.

30. Kuhnel B, Buetti E, Diggelmann H: Functional analysis of the glucocorticoid regulatory elements present in the mouse mammary tumor virus long terminal repeat. J Mol Biol 1986, 190:367-378.

31. Sleeman KE, Kendrick H, Ashworth A, Isacke CM, Smalley MJ: CD24 staining of mouse mammary gland cells defines luminal epithelial, myoepithelial/ basal and non-epithelial cells. Breast Cancer Res 2006, 8:R7.

32. Shackleton M, Vaillant F, Simpson KJ, Stingl J, Smyth GK, Asselin-Labat ML, Wu L, Lindeman GJ, Visvader JE: Generation of a functional mammary gland from a single stem cell. Nature 2006, 439:84-88.

33. Stingl J, Eirew P, Ricketson I, Shackleton M, Vaillant F, Choi D, Li HI, Eaves CJ: Purification and unique properties of mammary epithelial stem cells. Nature 2006, 439:993-997. 
34. Li C, Wong WH: Model-based analysis of oligonucleotide arrays: Expression index computation and outlier detection. Proc Natl Acad Sci USA 2001, 98:31-36.

35. Mouse Genome Informatics-Mammalian Orthology. [http://www. informatics.jax.org/orthology.shtml].

36. Herschkowitz JI, Simin K, Weigman VJ, Mikaelian I, Usary J, Hu Z, Rasmussen KE, Jones LP, Assefnia S, Chandrasekharan S, Backlund MG, Yin Y, Khramtzov Al, Bastein R, Quackenbush J, Glazer RI, Brown PH, Green JE, Kopelovich L, Furth PA, Palazzo JP, Olopade OI, Bernard PS, Churchill GA, Van Dyke T, Perou CM: Identification of conserved gene expression features between murine mammary carcinoma models and human breast tumors. Genome Biol 2007, 8:R76.

37. Cancer Biomedical Informatics Grid, National Cancer Institute: Distanceweighted discrimination.[https://cabig.nci.nih.gov/tools/DWD].

38. Marron JS, Todd MJ, Ahn J: Distance-Weighted Discrimination. Journal of American Statistical Association 2007, 102:1267-1271.

39. Shenkin PS, McDonald DQ: Cluster analysis of molecular conformations. J Comput Chem 1994, 15:899-916.

40. Saldanha AJ: Java Treeview-extensible visualization of microarray data. Bioinformatics 2004, 20:3246-3248

41. Gene Expression Omnibus. [http://www.ncbi.n/m.nih.gov/geo]

42. Liu Y, Hayes DN, Nobel A, Marron JS: Statistical significance of clustering for high dimension low sample size data. J Am Stat Assoc 2008, 103:1281-1293.

43. Monti S, Tamayo P, Mesirov J, Golub TR: Consensus clustering: a resampling-based method for class discovery and visualization of gene expression microarray data. Machine Learning 2003, 52:91-118.

44. Koziol JA, Maxwell DA, Fukushima M, Colmerauer ME, Pilch YH: A distribution-free test for tumor-growth curve analyses with application to an animal tumor immunotherapy experiment. Biometrics 1981, 37:383-390.

45. The Comprehensive R Archive Network: R 2.11.1. [http://cran.r-project. org].

46. Perou $C M$, Jeffrey SS, van de Rijn M, Rees CA, Eisen MB, Ross DT, Pergamenschikov A, Williams CF, Zhu SX, Lee JCF, Lashkari D, Shalon D, Brown PO, Botstein D: Distinctive gene expression patterns in human mammary epithelial cells and breast cancers. Proc Natl Acad Sci USA 1999, 96:9212-9217.

47. Charpin C, Secq V, Giusiano S, Carpentier S, Andrac L, Lavaut MN, Allasia C, Bonnier P, Garcia S: A signature predictive of disease outcome in breast carcinomas, identified by quantitative immunocytochemical assays. Int J Cancer 2009, 124:2124-2134.

48. Gil MP, Bohn E, O'Guin AK, Ramana CV, Levine B, Stark GR, Virgin HW, Schreiber RD: Biologic consequences of STAT1-independent IFN signaling. Proc Natl Acad Sci USA 2001, 98:6680-6685.

49. Wang D, Coscoy L, Zylberberg M, Avila PC, Boushey HA, Ganem D, DeRisi JL: Microarray-based detection and genotyping of viral pathogens. Proc Natl Acad Sci USA 2002, 99:15687-15692.

50. Cardiff RD, Anver MR, Boivin GP, Bosenberg MW, Maronpot RR, Molinolo AA, Nikitin AY, Rehg JE, Thomas GV, Russell RG, Ward JM: Precancer in mice: animal models used to understand, prevent, and treat human precancers. Toxicol Pathol 2006, 34:699-707.

51. Lee S, Mohsin SK, Mao S, Hilsenbeck SG, Medina D, Allred DC: Hormones, receptors, and growth in hyperplastic enlarged lobular units: early potential precursors of breast cancer. Breast Cancer Res 2005, 8:R6.

52. Davidson NE: Ovarian ablation as adjuvant therapy for breast cancer. $J$ Natl Cancer Inst Monogr 2001, 30:67-71.

53. Levy DE, Darnell JE Jr: STATs: Transcriptional control and biological impact. Rev Cell Biol 2002, 3:651-662.

54. Presneau N, Manderson EN, Tonin PN: The quest for a tumor suppressor gene phenotype. Curr Mol Med 2003, 3:605-629.

55. Varinou L, Ramsauer K, Karaghiosoff M, Kolbe T, Pfeffer K, Muller M, Decker T: Phosphorylation of the Stat1 transactivation domain is required for full-fledged IFNץ-dependent innate immunity. Immunity 2003, 19:793-802.

56. Xi S, Dyer KF, Kimak M, Zhang Q, Gooding WE, Chaillet JR, Chai RL, Ferrell RE, Zamboni B, Hunt J, Grandis JR: Decreased STAT1 expression by promoter methylation in squamous cell carcinogenesis. J Nat/ Cancer Inst 2006, 98:181-189.
57. Mishra DK, Chen Z, Wu Y, Sarkissyan M, Koeffler HP, Vadgama JV: Global methylation pattern of genes in androgen-sensitive and androgenindependent prostate cancer cells. Mol Cancer Ther 9:33-45.

58. Asselin-Labat ML, Shackleton M, Stingl J, Vaillant F, Forrest NC, Eaves CJ, Visvader JE, Lindeman GJ: Steroid hormone receptor status of mouse mammary stem cells. J Natl Cancer Inst 2006, 98:1011-1014.

59. Kovarik P, Stoiber D, Novy M, Decker T: Stat1 combines signals derived from IFN-gamma and LPS receptors during macrophage activation. Embo J 1998, 17:3660-3668.

60. Kovarik P, Mangold M, Ramsauer K, Heidari H, Steinborn R, Zotter A, Levy DE, Muller M, Decker T: Specificity of signaling by STAT1 depends on $\mathrm{SH} 2$ and C-terminal domains that regulate Ser727 phosphorylation, differentially affecting specific target gene expression. Embo J 2001, 20:91-100

61. EBCTCG: Effects of chemotherapy and hormonal therapy for early breast cancer on recurrence and 15-year survival: an overview of the randomised trials. Lancet 2005, 365:1687-1717.

62. Harichand-Herdt S, Zelnak A, O'Regan R: Endocrine therapy for the treatment of postmenopausal women with breast cancer. Expert Rev Anticancer Ther 2009, 9:187-198.

63. Davies C, Godwin J, Gray R, Clarke M, Cutter D, Darby S, McGale P, Pan HC, Taylor C, Wang YC, Dowsett M, Ingle J, Peto R: Relevance of breast cancer hormone receptors and other factors to the efficacy of adjuvant tamoxifen: patient-level meta-analysis of randomised trials. Lancet 2011 378:771-784.

doi: $10.1186 / \mathrm{bcr} 3100$

Cite this article as: Chan et al: STAT1-deficient mice spontaneously develop estrogen receptor $\alpha$-positive luminal mammary carcinomas. Breast Cancer Research 2012 14:R16.

\section{Submit your next manuscript to BioMed Central and take full advantage of:}

- Convenient online submission

- Thorough peer review

- No space constraints or color figure charges

- Immediate publication on acceptance

- Inclusion in PubMed, CAS, Scopus and Google Scholar

- Research which is freely available for redistribution

Submit your manuscript at www.biomedcentral.com/submit
C) Biomed Central 